\title{
Linking in-situ charge accumulation to electronic structure in doped SrTiO3 reveals design principles for hydrogen evolving photocatalysts
}

Article

Accepted Version

Moss, B., Wang, Q., Butler, K. T., Grau-Crespo, R. ORCID: https://orcid.org/0000-0001-8845-1719, Selim, S., Regoutz, A., Hisatomi, T., Godin, R., Payne, D. J., Katizas, A. G., Domen, K., Steir, L. and Durrant, J. R. (2021) Linking in-situ charge accumulation to electronic structure in doped $\mathrm{SrTiO}$ reveals design principles for hydrogen evolving photocatalysts. Nature Materials, 20. pp. 511-517. ISSN 1476-1122 doi: https://doi.org/10.1038/s41563-020-00868-2 Available at https://centaur.reading.ac.uk/93917/

It is advisable to refer to the publisher's version if you intend to cite from the work. See Guidance on citing.

To link to this article DOI: http://dx.doi.org/10.1038/s41563-020-00868-2

Publisher: Nature Publishing Group

All outputs in CentAUR are protected by Intellectual Property Rights law, including copyright law. Copyright and IPR is retained by the creators or other copyright holders. Terms and conditions for use of this material are defined in 
the End User Agreement.

www.reading.ac.uk/centaur

\section{CentAUR}

Central Archive at the University of Reading

Reading's research outputs online 


\section{Linking in-situ charge accumulation to electronic structure in doped $2 \mathrm{SrTiO}_{3}$ reveals design principles for hydrogen evolving photocatalysts.}

3 Benjamin Moss ${ }^{1,2}$, Qian Wang ${ }^{3,4}$, Keith T. Butler ${ }^{5}$, Ricardo Grau-Crespo ${ }^{6}$ Shababa Selim ${ }^{1,2}$, 4 Anna Regoutz ${ }^{7}$, Takashi Hisatomi ${ }^{8}$, Robert Godin ${ }^{1,9}$, David J. Payne ${ }^{10}$, Andreas Kafizas ${ }^{1,11}$, 5 Kazunari Domen ${ }^{6,12}$, Ludmilla Steier ${ }^{1 *}$ and James R. Durrant ${ }^{1,2}$

\footnotetext{
${ }^{1}$ Department of Chemistry, Imperial College London, London, W12 0BZ, UK

${ }^{2}$ Centre for Plastic Electronics, Imperial College London, Prince Consort Road, London SW7 2BZ, UK

${ }^{3}$ Department of Chemical System Engineering, School of Engineering, The University of Tokyo, 7-31 Hongo, Bunkyo-ku, Tokyo 113-8656, Japan

${ }^{4}$ Department of Chemistry, University of Cambridge, Lensfield Road, Cambridge CB2 1EW, UK

${ }^{5}$ SciML, Scientific Computing Division, Rutherford Appleton Laboratory, Harwell, OX11 0QX, UK

${ }^{6}$ Department of Chemistry, University of Reading, Whiteknights, Reading, RG6 6AD, UK

${ }^{7}$ Department of Chemistry, University College London, 20 Gordon Street, London, WC1H 0AJ, UK

${ }^{8}$ Research Initiative for Supra-Materials, Interdisciplinary Cluster for Cutting Edge Research, Shinshu University, 4-17-1 Wakasato, Nagano-shi, Nagano 380-8553, Japan

${ }^{9}$ Department of Chemistry, University of British Columbia, Kelowna, BC, V1V 1V7, Canada

${ }^{10}$ Department of Materials, Imperial College London, London, SW7 2AZ, UK

${ }^{11}$ Grantham Institute, Imperial College London, London, SW7 4AZ, UK

${ }^{12}$ Office of University Professor, The University of Tokyo, 7-3-1 Hongo, Bunkyo-ku, Tokyo 1138656, Japan

* correspondence to: 1.steier@imperial.ac.uk
} 


\begin{abstract}
Recently, record solar to hydrogen efficiencies have been demonstrated using La,Rh codoped $\mathrm{SrTiO}_{3}\left(\mathrm{La}, \mathrm{Rh}: \mathrm{SrTiO}_{3}\right)$ incorporated into a low cost and scalable Z-scheme device, known as a photocatalyst sheet. However, the unique properties that enable $\mathrm{La}, \mathrm{Rh}: \mathrm{SrTiO}_{3}$ to support this impressive performance are not fully understood. Combining in-situ spectroelectrochemical measurements with density functional theory and photoelectron spectroscopy produces a depletion model of $\mathrm{Rh}: \mathrm{SrTiO}_{3}$ and $\mathrm{La}, \mathrm{Rh}: \mathrm{SrTiO}_{3}$ photocatalyst sheets. This reveals remarkable properties, such as deep flatband potentials ( $+2 \mathrm{~V}_{\mathrm{RHE}}$ ) and a Rh oxidation state dependent reorganisation of the electronic structure, involving the loss of a vacant $R h 4 d$ mid gap state. This reorganisation enables $\mathrm{Rh}: \mathrm{SrTiO}_{3}$ to be reduced by co-doping without compromising ptype character. In-situ time resolved spectroscopies show the electronic structure reorganisation induced by $\mathrm{Rh}$ reduction controls electron lifetime in photocatalyst sheets. In Rh:SrTiO potentials, where the complete $Z$-scheme operates inefficiently. La co-doping fixes $R h$ in the $3+$ state, resulting in long-lived photogenerated electrons even at very positive potentials ( $\left.+1 \mathrm{~V}_{\mathrm{RHE}}\right)$, where both components of the complete device operate effectively. This understanding of role of co-dopants provides new insight into the design principles for water splitting devices based on bandgap engineered metal oxides.
\end{abstract}

Wide band gap binary and ternary metal oxides such as $\mathrm{TiO}_{2},{ }^{1} \mathrm{SrTiO}_{3},{ }^{2}$ are often considered benchmark photocatalysts due to their chemical stability, low-cost and high quantum yields ( $>70 \%$ for unassisted water splitting) ${ }^{3,4}$ However, their large optical band gap limits solar harvesting to the UV and solar-to-hydrogen (STH) conversion efficiency to $\sim 2 \%{ }^{5}$ One potential strategy to introduce visible light absorption is to modify the band structure of wide band gap oxides. For example, visible light harvesting in $\mathrm{TiO}_{2}$ has been achieved through doping with carbon ${ }^{6}$, nitrogen ${ }^{7}$ or transition metals. ${ }^{8,9}$ Improvements have been chequered, uncovering significant challenges in translating enhanced visible light harvesting into improved STH efficiency. ${ }^{1,10}$ With notable exceptions, ${ }^{6,7}$ marginal gains or even losses in overall photon conversion efficiency are generally observed in most studies, despite improved light absorption. ${ }^{9,11,12}$ The reasons for these losses are often unclear, but are broadly attributed to the inadvertent formation of localised dopant states, associated with short carrier diffusion lengths and low conductivities, and/or charge compensating defect levels, which may act as recombination centres. ${ }^{13,14}$ As such, doping for visible light activity has often been suggested to be a less promising strategy for producing efficient photocatalysts in comparison to other methods. ${ }^{14,15-22}$

Recently Domen and co-workers have demonstrated a band gap engineered wide band gap oxide ( $\mathrm{La}, \mathrm{Rh}$ co-doped $\mathrm{SrTiO}_{3}$ ) exhibiting QYs in the visible of 33\% and overall $\mathrm{STH}$ efficiencies exceeding $1 \%$ using a 'photocatalyst sheet' device architecture. ${ }^{23-26}$ This represents a record for a Z-scheme water splitting device. Sheets are constructed by embedding a layer of n-type $\mathrm{Mo}: \mathrm{BiVO}_{4}$ and p-type $\mathrm{La}, \mathrm{Rh}: \mathrm{SrTiO}_{3}$ semiconducting particles into a solid conductive mediator such as gold or carbon. Pioneering ex-situ studies of $\mathrm{Rh}: \mathrm{SrTiO}_{3}{ }^{27-31}$ powders have indicated that $\mathrm{Rh}^{4+}$ substitution at $\mathrm{Ti}^{4+}$ sites introduces filled $\mathrm{Rh}$ states above the $\mathrm{SrTiO}_{3}$ valence band (VB) as well as a vacant mid gap state. ${ }^{27}$ Reduction of $\mathrm{Rh}^{4+}$ to $\mathrm{Rh}^{3+}$ by chemical reduction or co-doping supresses this state. ${ }^{27,29}$ Electron trapping in $\mathrm{Rh}: \mathrm{SrTiO}_{3}$ has been previously observed in ex-situ transient absorption experiments on nanosecond timescales and was attributed to trapping in the vacant mid gap state, thus explaining the low efficiency of $\mathrm{Rh}^{4+}$ doped systems. ${ }^{11-14}$ However, the absence of a semiconductor electrolyte interface in these studies means that the intrinsic capacity of $\mathrm{Rh}: \mathrm{SrTiO}_{3}$ and related materials to separate charge remains unexplored. Further, key 
56 operational parameters such as the potential drop when contacted with electrolyte remain

57 unmeasured, limiting understanding of the factors that may facilitate charge separation in this 58 remarkable material. ${ }^{27,29}$ Herein, we combine time resolved optical spectroscopies 59 performed in situ on (La), $\mathrm{Rh}: \mathrm{SrTiO}_{3}$ photocatalyst sheets with direct electronic structure 60 measurements supported by density functional theory (DFT) to reveal the remarkable 61 interplay between Fermi level position, $\mathrm{Rh} 4 \mathrm{~d}$ structure and band bending/charge separation 62 in $\mathrm{Rh}: \mathrm{SrTiO}_{3}$ materials.

63 Figures 1a-b show optical absorption spectra and photographs of $\mathrm{SrTiO}_{3}, \mathrm{Rh}: \mathrm{SrTiO}_{3}$, 64 hydrogen reduced $\mathrm{Rh}: \mathrm{SrTiO}_{3}\left(\mathrm{H}_{2}-\mathrm{Rh}: \mathrm{SrTiO}_{3}\right)$ and $\mathrm{La}, \mathrm{Rh}: \mathrm{SrTiO}_{3}$ powders used to fabricate 65 photocatalyst sheets. XRD showed all powders to be phase pure - consisting of single 66 perovskite phase (Supplementary Fig. S0). Upon doping $\mathrm{SrTiO}_{3}$ with $\mathrm{Rh}$, a purple powder is 67 obtained showing a $0.4 \mathrm{eV}$ red-shift in the effective optical band gap (Tauc plots in 68 Supplementary Fig. S1) alongside two strongly broadened sub-bandgap absorption features 69 between $\sim 500-800 \mathrm{~nm}$ and $\sim 900-1200 \mathrm{~nm}$. After chemically reducing $\mathrm{Rh}: \mathrm{SrTiO}_{3}$ in a 70 hydrogen atmosphere, the powder turns bright yellow and the absorption spectrum shows a 71 further red-shift in the effective band edge and the disappearance of the additional absorption 72 features, consistent with previous observations. ${ }^{8,27}$ XPS indicates the reduction of $\mathrm{Rh}^{4+}$, 73 predominantly to $\mathrm{Rh}^{3+}$ (Supplementary Fig. S2.1-S2.3). A similar effect is observed when $74 \mathrm{Rh}: \mathrm{SrTiO}_{3}$ is co-doped with La. Here, a light-yellow powder is obtained. XPS reveals a $75 \mathrm{Rh}:$ La ratio of $1: 1$ in our samples and the reduction of $\mathrm{Rh}^{4+}$ to $\mathrm{Rh}^{3+}$. This is in agreement with 76 previous studies which reported that $\mathrm{La}^{3+}$ substitution at $\mathrm{Sr}^{2+}$ sites can effectively facilitate 77 the reduction of $\mathrm{Rh}^{4+}$ to $\mathrm{Rh}^{3+}$ via an ionic charge compensation mechanism, ${ }^{23,29,30}$ and shows 78 that La co-doping has an effect analogous to chemical reduction.
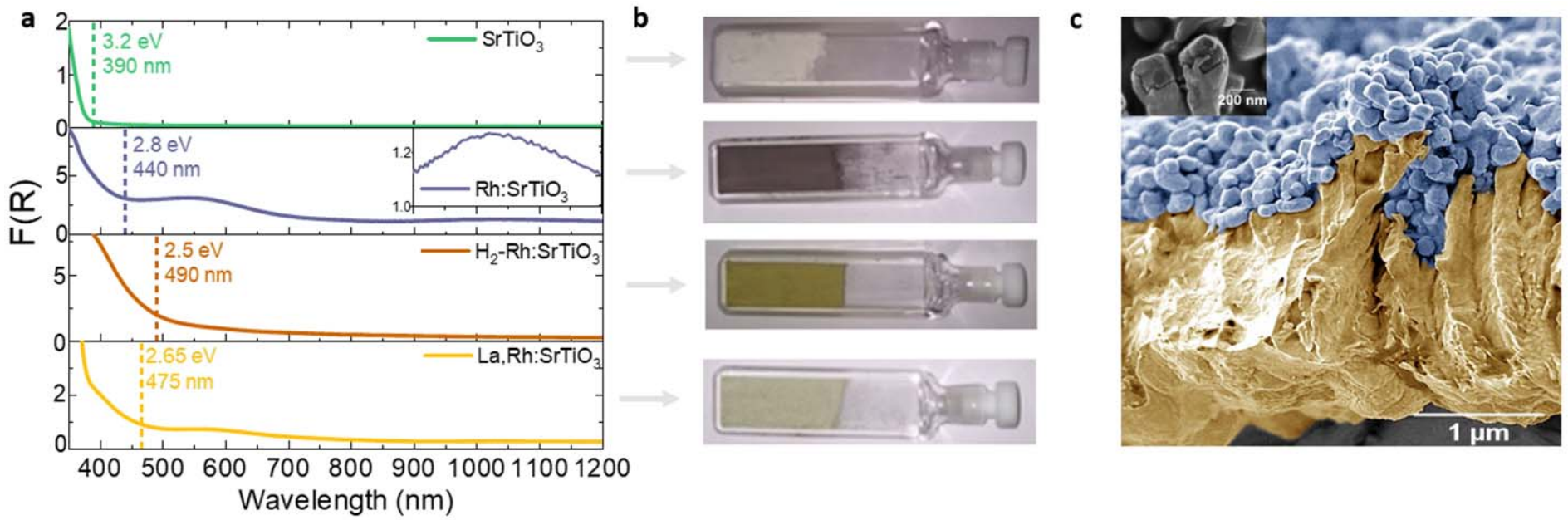

Figure 1. The colour of doped and undoped $\mathrm{SrTiO}_{3}$ powders and the morphology of photocatalyst sheets. (a) Optical absorption spectra, plotted in dimensionless units of the Kubelka-Munk function, $\mathrm{F}(\mathrm{R})$, for $\mathrm{SrTiO}_{3}$, Rh doped $\mathrm{SrTiO}_{3}\left(\mathrm{Rh}: \mathrm{SrTiO}_{3}\right)$, hydrogen reduced Rh:SrTiO $\left(\mathrm{H}_{2}-\mathrm{Rh}: \mathrm{SrTiO}_{3}\right)$ and $\mathrm{La}$, Rh co-doped $\mathrm{SrTiO}_{3}\left(\mathrm{La}, \mathrm{Rh}: \mathrm{SrTiO}_{3}\right)$. Dotted lines show the fitted effective optical band gap extracted from Supplementary Fig. S1. (b) Photographs of the powders to indicate the color of the aforementioned materials. (c) A typical cross-sectional SEM image of the photocatalyst sheets studied herein, showing a monolayer of partially sintered ( $\mathrm{La}$ ), $\mathrm{Rh}_{\mathrm{S}} \mathrm{SrTiO}_{3}$ particles (blue) embedded (see inset) in a $2 \mu \mathrm{m}$ thick gold back contact (yellow). This is colored according to EDX mapping results (Supplementary Fig. S3).

79 We fabricated photocatalyst sheet half-electrodes from these powders using a modified 80 particle transfer method (see Methods). Cross-sectional scanning electron microscopy (SEM) 81 images (Fig. 1c, EDX mapping in Supplementary Fig. S3) show that these modified 82 photocatalyst sheets consist of a layer of partially sintered oxide particles embedded in a $832 \mu \mathrm{m}$ thick Au back contact. These photocatalyst sheet half-electrodes permit us to study the 84 properties of $\mathrm{Rh}: \mathrm{SrTiO}_{3}$ and $\mathrm{La}, \mathrm{Rh}: \mathrm{SrTiO}_{3}$ under operational conditions, meaning in 85 electrolyte solution, under illumination and in the potential window a z-scheme device is 
86 likely to operate during water splitting. As such the results shown in Figure 2 track electrode

87 processes and transformation in situ and thus differ from ex situ studies published thus far.

88 Spectroelectrochemical (SEC) measurements of a $\mathrm{Rh}: \mathrm{SrTiO}_{3}$ photocatalyst sheet shown in

89 Figure 2a track the change in optical absorption at the surface of $\mathrm{Rh}: \mathrm{SrTiO}_{3}$ as the potential is

90 varied from 1.1 $\mathrm{V}_{R H E}$ towards $-0.2 V_{R H E}$. The differential absorption spectra at more negative

91 potentials show a redshift in absorption around the effective band edge (positive $\Delta \mathrm{F}(\mathrm{R})$ ) that

92 occurs in concert with the loss of absorption from the sub-band gap features (negative

$93 \Delta \mathrm{F}(\mathrm{R})$ ). This trend is reversible when the potential is scanned in the opposite direction

94 (Supplementary Fig. $\mathrm{S} 4 \mathrm{a}$ ). $\Delta \mathrm{F}(\mathrm{R})$ of the sub-band gap features exhibits sigmoidal behaviour

95 with respect to applied potential, typical of a redox couple, with $\mathrm{E}_{1 / 2}$ located at $0.52 \mathrm{~V}_{R H E}$

96 (Supplementary Fig. S4b and Fig. 2f discussed further below). A similar differential

97 absorption spectrum can be obtained by subtracting the absorption spectrum of $\left(\mathrm{Rh}^{4+}\right)$

$98 \mathrm{Rh}: \mathrm{SrTiO}_{3}$ from $\left(\mathrm{Rh}^{3+}\right) \mathrm{H}_{2}-\mathrm{Rh}: \mathrm{SrTiO}_{3}$ (Fig. 2b). We therefore attribute the optical changes

99 observed in $\mathrm{Rh}: \mathrm{SrTiO}_{3}$ photocatalyst sheets under applied potential to the reversible

100 reduction of $\mathrm{Rh}^{4+}$ to $\mathrm{Rh}^{3+}$ within the space charge layer. This is corroborated by cyclic

101 voltammograms showing a reversible redox wave within the same potential window

102 (Supplementary Fig. S4c). In contrast, the optical absorption of $\mathrm{La}, \mathrm{Rh}: \mathrm{SrTiO}_{3}$ sheets shows

103 negligible absorption changes over this potential range (Supplementary Fig. S4d), consistent

104 with an ionic charge compensation mechanism, which fixes $\mathrm{Rh}$ predominantly in the $3+$

105 oxidation state independent of applied bias. 

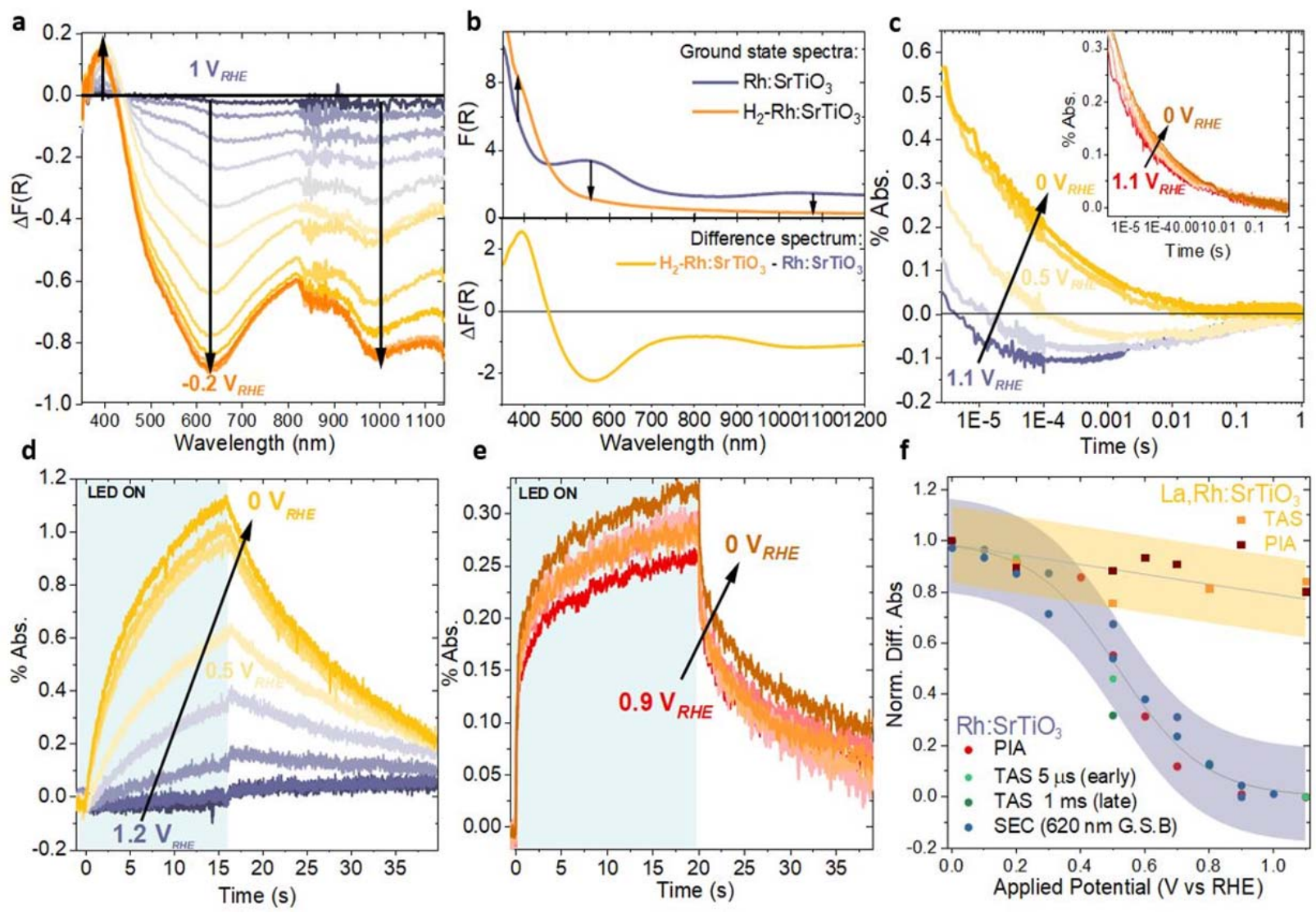

Figure 2. Connecting the $\mathrm{Rh}$ oxidation state to charge carrier dynamics of (La,)Rh:SrTiO ${ }_{3}$ photocatalyst sheets. (a) Spectroelectrochemical (SEC) difference spectra of $\mathrm{Rh}: \mathrm{SrTiO}_{3}$ photocatalyst sheets, showing the change in optical absorption upon applying negative potentials in comparison to a reference spectrum taken at $1.1 V_{R H E}\left[\Delta \mathrm{F}(\mathrm{R})=\mathrm{F}\left(\mathrm{R}\left(\mathrm{V}_{\text {applied }}\right)\right)-\mathrm{F}\left(\mathrm{R}\left(1.1 V_{R H E}\right)\right)\right](\mathrm{b}) \mathrm{The}$ absorption spectra of $\mathrm{Rh}: \mathrm{SrTiO}_{3}$ and $\mathrm{H}_{2}-\mathrm{Rh}_{\mathrm{SrTiO}}$ (top) can be subtracted to produce a difference spectrum $\left[\Delta \mathrm{F}(\mathrm{R})=\mathrm{F}\left(\mathrm{R}\left(\mathrm{H}_{2}-\mathrm{Rh}: \mathrm{SrTiO} \mathrm{O}_{3}\right)\right)-\right.$ $\left.\mathrm{F}\left(\mathrm{R}\left(\mathrm{Rh}: \mathrm{SrTiO}_{3}\right)\right)\right]$ (bottom) similar to that seen in (a). (c) Transient absorption kinetics of electrons in $\mathrm{Rh}_{\mathrm{SrTiO}} \mathrm{S}_{3}$ and $\mathrm{La}, \mathrm{Rh}: \mathrm{SrTiO}_{3}$ (inset) photocatalyst sheets measured over a range of applied potentials $\left(1.1,0.8,0.5,0.3\right.$ and $\left.0 V_{R H E}\right)$. Samples were excited with a $355 \mathrm{~nm}$ laser pulse $\left(7 \mathrm{~ns}, 400 \mu \mathrm{J} / \mathrm{cm}^{2}\right)$ with a $1250 \mathrm{~nm}$ probe light used to monitor electrons. (d) Photoinduced absorption (PIA) kinetics in $\mathrm{Rh}: \mathrm{SrTiO}_{3}$ and (e) $\mathrm{La}, \mathrm{Rh}: \mathrm{SrTiO}_{3}$ photocatalyst sheets at various applied potentials, tracking conduction band electrons monitored at $1250 \mathrm{~nm}$. The sample was irradiated with $365 \mathrm{~nm}$ LED light for several seconds $\left(8 \mathrm{~mW} \mathrm{~cm}{ }^{-2}\right.$, shaded region) before the LED was switched off again. (f) Overlay of normalised differential absorption as a function of potential extracted from: i) the $620 \mathrm{~nm}$ bleaching signal in SEC, normalised against the bleaching minimum at $620 \mathrm{~nm}$ and $0 \mathrm{~V}_{R H E}$ (Fig. 2a) ii) TA signals measured at $5 \mu$ s and 1 ms normalised against the $0 \mathrm{~V}_{\mathrm{RHE}}$ signal at these times (Fig. 2c) and iii) the maximum PIA amplitude, normalised using the PIA maximum at $0 \mathrm{~V}_{\mathrm{RHE}} \quad$ (Fig. 2d,e) for Rh:SrTiO${ }_{3}$ and $\mathrm{La}, \mathrm{Rh}: \mathrm{SrTiO}_{3}$ photocatalyst sheets. All data points for $\mathrm{Rh}: \mathrm{SrTiO}_{3}$ sheets were then fitted to a sigmoidal (logistic decay type) function, yielding a midpoint at $0.52 \mathrm{~V}_{\mathrm{RHE}}$. A linear function was used to fit datapoints for La, $\mathrm{Rh}_{\mathrm{S}} \mathrm{SrTiO}_{3}$ sheets. Electrolyte in all measurements: $0.1 \mathrm{M} \mathrm{Na}_{2} \mathrm{SO}_{4}$ solution $(\mathrm{pH} 7)$.

Figure 2c shows potential dependent transient absorption (TA) of (La), $\mathrm{Rh}: \mathrm{SrTiO}_{3}$ photocatalyst sheet half-electrodes. We excited samples with a UV laser flash and monitored 108 the kinetics at $1250 \mathrm{~nm}$, spanning the $\mu$ s-s timescales relevant to water splitting reactions ${ }^{32}$. 109 TA studies of $\mathrm{SrTiO}_{3}$ and $\mathrm{La}, \mathrm{Rh}: \mathrm{SrTiO}_{3}$ using electron and hole scavengers (Supplementary 110 Fig. S5.1-5.2) indicate that $1250 \mathrm{~nm}$ probes the absorption of photogenerated electrons 111 relatively close in energy to the conduction band (hereafter ' $\mathrm{CB}$ electrons', though we note 112 that in oxide materials these $\mathrm{CB}$ electrons are not necessarily of the same nature as early 113 timescale (i.e. ps-ns) free electrons in the CB). In $\mathrm{La}, \mathrm{Rh}: \mathrm{SrTiO}_{3}$ sheets (inset Fig. 2c), a 114 positive $1250 \mathrm{~nm}$ transient absorption is observed, showing power law decay kinetics 115 invariant over the range of potentials studied (TA analysis in Supplementary Fig. 5.3a). Only 116 a modest initial amplitude dependence on applied potential $(<10 \%)$ is found. In the case of $117 \mathrm{Rh}: \mathrm{SrTiO}_{3}$ photocatalyst sheets, the TA kinetics show two distinct decay regimes governed 118 by applied potential. At positive potentials (e.g. $1.1 V_{R H E}$ ) a transient bleach (loss of 
119 absorption) is observed on the $\mu$ s-ms timescale. SEC of $\mathrm{Rh}: \mathrm{SrTiO}_{3}$ sheets (Fig. 2a) indicates 120 that a loss of sub-band gap absorption is associated with the removal of $\mathrm{Rh}^{4+}$ states from the 121 system. Consequently, we attribute the $1250 \mathrm{~nm}$ bleach observed in $\mathrm{Rh}: \mathrm{SrTiO}_{3}$ sheets at 122 positive applied potentials to a loss of $\mathrm{Rh}^{4+}$ states after excitation, presumably related to electron trapping by $\mathrm{Rh}^{4+}$ states. This is in agreement with ex-situ observations made by Murthy et $a l^{33}$ and is also concordant with a linear dependence of the amplitude of this feature on laser intensity (Supplementary Fig. 5.3b,c). In contrast, at potentials close to 0 $V_{R H E}$, positive transients are observed with power law decay kinetics identical to $\mathrm{La}, \mathrm{Rh}: \mathrm{SrTiO}_{3}$ (Supplementary Fig. S5.3d). By extension, we therefore also assign absorption at $1250 \mathrm{~nm}$ in $\mathrm{Rh}: \mathrm{SrTiO}_{3}$ sheets at negative applied potentials to $\mathrm{CB}$ electrons. A change in the fate of photogenerated electrons in $\mathrm{Rh}: \mathrm{SrTiO}_{3}$ photocatalyst sheets is further supported by the TA spectrum of Rh:SrTiO 3 (Supplementary Fig. S5.4a), which is similar to La,Rh:SrTiO at negative potentials but dissimilar at positive potentials (Supplementary Fig. S5.4b).

To evaluate photocatalyst sheets under operational conditions and study the accumulation of charges at the oxide surface available for catalysis, we monitored electron dynamics (1250 $\mathrm{nm}$ probe) during and after long pulse illumination (15-20s) with a $365 \mathrm{~nm}$ LED (Fig. 2d-e and Methods). The resulting photoinduced absorption (PIA) spectra of $\mathrm{Rh}: \mathrm{SrTiO}_{3}$ and $\mathrm{La}, \mathrm{Rh}: \mathrm{SrTiO}_{3}$ sheets (Supplementary Fig. S5.5a-c) exhibit a similar shape and potential dependence to the respective TA spectra (Supplementary Fig. 5.4a,b), indicating that the same species are monitored at $1250 \mathrm{~nm}$ in both experiments. We observe that electron accumulation during irradiation is strongly potential-dependent in $\mathrm{Rh}: \mathrm{SrTiO}_{3}$ photocatalyst sheets (Fig. 2d), but broadly potential-independent in $\mathrm{La}, \mathrm{Rh}: \mathrm{SrTiO}_{3}$ sheets (Fig. 2e). At positive potentials (e.g. 1.1 $V_{R H E}$ ) $\mathrm{Rh}: \mathrm{SrTiO}_{3}$ shows a small ground state bleach. This signal transforms into a growing positive absorption as the applied potential approaches $0 V_{R H E}$. After the LED is turned off, the small bleach signal at positive applied potentials recovers on a similar timescale ( $\sim 100 \mathrm{~ms})$ to that seen in TAS (Fig. 2c). In contrast, at negative potentials, absorption signals persist for tens of seconds after the LED is turned off.

Figure $2 \mathrm{f}$ summarises the potential dependence of our in-situ studies; plotting signal amplitudes of SEC (Fig. 2a), TA (Fig 2c) and PIA (Fig. 2d,e) against electrode potential for $\mathrm{Rh}: \mathrm{SrTiO}_{3}$ and $\mathrm{La}, \mathrm{Rh}: \mathrm{SrTiO}_{3}$ photocatalyst sheets. In $\mathrm{Rh}: \mathrm{SrTiO}_{3}$ photocatalyst sheets, normalised TA signals, as well as the maximum PIA amplitude of accumulated electrons track the redox wave behaviour of our SEC measurements (Supplementary Fig. S4b). This overlay clearly shows that the photogeneration of long-lived conduction band electrons is strongly linked to $\mathrm{Rh}^{4+}$ reduction in $\mathrm{Rh}: \mathrm{SrTiO}_{3}$ sheets. In summary, this data indicates that under operational conditions, $\mathrm{Rh}: \mathrm{SrTiO}_{3}$ photocatalyst sheets only generate long-lived electrons for biases $<<0.52 V_{R H E}$ (i.e. $E^{\mathrm{Rh} 4+/ \mathrm{Rh} 3+}$ ), whilst $\mathrm{La}, \mathrm{Rh}: \mathrm{SrTiO}_{3}$ sheets produce long-lived electrons even under strongly positive $\left(+1 \mathrm{~V}_{\mathrm{RHE}}\right)$ potentials. As we later discuss, the ability to accumulate charge at positive potentials is critical to the efficient operation of the complete water splitting Z-scheme in photocatalyst sheets. 

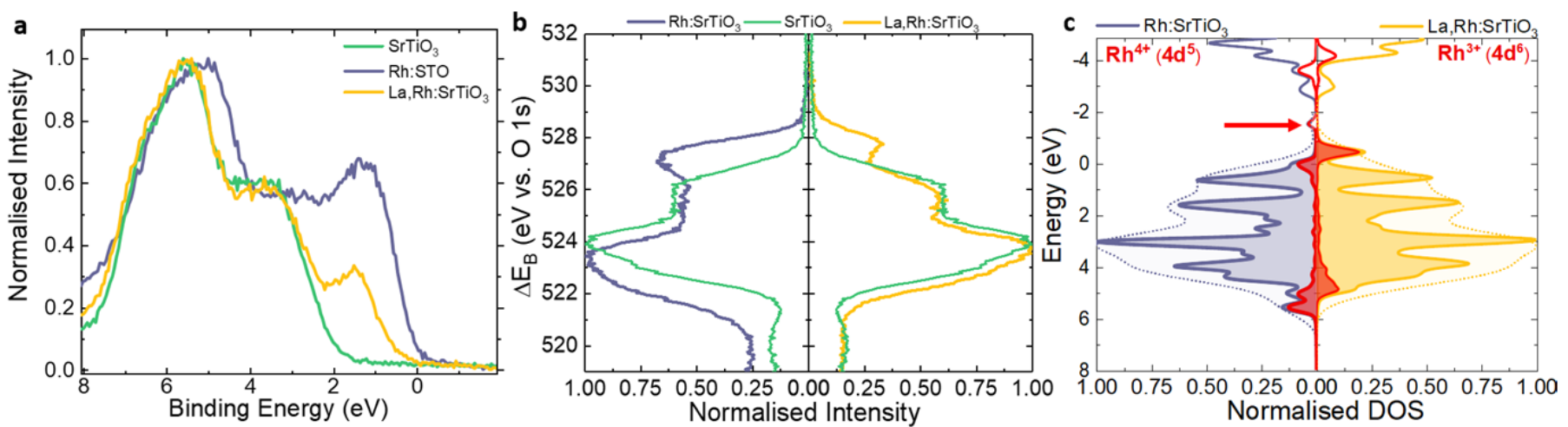

Figure 3. Effect of $\mathbf{R h}$ and La doping on theoretical and experimental band structure of $\mathrm{SrTiO}_{3}$. (a) Valence XPS spectra of $\mathrm{SrTiO}_{3}$, $\mathrm{Rh}: \mathrm{SrTiO}_{3}$, and $\mathrm{La}, \mathrm{Rh}: \mathrm{SrTiO}_{3}$. The larger area of the peak introduced by Rh doping in $\mathrm{Rh}: \mathrm{SrTiO}_{3}$ is attributed to increased surface segregation of $\mathrm{Rh}$ in $\mathrm{Rh}: \mathrm{SrTiO}_{3}$ (Supplementary Fig. S2.1, Table S1).(b) VB spectra of the samples on the $\Delta \mathrm{E}_{\mathrm{B}}$ scale enable direct comparison of the energy of the Rh dopant states. (c)The density of states calculated by hybrid DFT, aligned using $02 p$ states and weighted by the elemental single electron ionisation cross-section for the Al $\mathrm{K} \alpha \mathrm{X}$-rays used in our XPS studies. $\mathrm{Rh} 4 \mathrm{~d}$ states are shown in red. To approximate further broadening, an additional gaussian broadening was applied to the peaks, leading to the envelope shown by the dotted line. Unlike XPS, DFT also gives the density of unoccupied states. The red arrow points to an unoccupied $\mathrm{Rh}$ state in the mid gap of $\mathrm{Rh}_{\mathrm{SrTiO}} \mathrm{Sthat}_{3}$ is absent in $\mathrm{La}, \mathrm{Rh}: \mathrm{SrTiO}_{3}$.

160 To better understand the link between the fundamental photophysical properties of 161 (La), $\mathrm{Rh}: \mathrm{SrTiO}_{3}$ and the oxidation state of $\mathrm{Rh}$, we turn to DFT-supported VB XPS. 162 Comparing VB spectra of $\mathrm{SrTiO}_{3}, \mathrm{Rh}: \mathrm{SrTiO}_{3}$ and $\mathrm{La}, \mathrm{Rh}: \mathrm{SrTiO}_{3}$ (Fig. 3a), we observe a 163 significant Fermi level $\left(\mathrm{E}_{\mathrm{F}}\right)$ shift in both Rh-doped oxides towards the effective VB edge, 164 consistent with p-type conductivity as observed by Kudo et al. ${ }^{34} \mathrm{E}_{\mathrm{F}}$ of $\mathrm{SrTiO}_{3}, \mathrm{Rh}: \mathrm{SrTiO}_{3}$ and $165 \mathrm{La}, \mathrm{Rh}: \mathrm{SrTiO}_{3}$ is located $\sim 1.8 \mathrm{eV}, \sim 0.1 \mathrm{eV}$ and $\sim 0.3 \mathrm{eV}$ above their respective $\mathrm{VB}$ edges 166 (linear extrapolation see Supplementary Fig. S2.1f). As a result, all peaks shift in accordance 167 with the observed Fermi level change seen in the VB spectrum (Supplementary Figure $168 \mathrm{~S} 2.2 \mathrm{a}$ ), consistent with previous observations of $\mathrm{Rh}$ doped oxides. ${ }^{35,36}$ This effect prevents 169 direct comparison of relative energies of $\mathrm{Rh}$ states in the $\mathrm{VB}$ region on the binding energy $170 \quad\left(\mathrm{E}_{\mathrm{B}}\right)$ scale. ${ }^{35}$ However, the binding energy relative to lattice $\mathrm{O}^{2-}$ in the $\mathrm{O} 1 \mathrm{~s}$ spectrum $\left(\Delta \mathrm{E}_{\mathrm{B}} \mathrm{vs}\right.$ $171 \mathrm{O}$ 1s) should be independent of this effect ${ }^{36}$ (Supplementary Figure S2.2a and accompanying 172 equation). Comparison of the VB spectra of doped and undoped materials, plotted relative to 173 the lattice $\mathrm{O}^{2-}$ binding energy (Fig. 3b), allows us to see that $\mathrm{Rh}$ doping introduces states 174 above the VB maximum and below the VB minimum of $\mathrm{SrTiO}_{3}$, leading to a broadening of the VB envelope and a narrowing of the effective band gap, consistent with our observations in Fig. 1a. Closer inspection of the region around the VB maximum (Supplementary Fig. $\mathrm{S} 2.2 \mathrm{~b}$ ) shows that the states introduced by Rh doping are shifted to higher energy upon La co-doping. The same effect is also observed when $\mathrm{Rh}_{\mathrm{SrTiO}}$ is reduced in a hydrogen atmosphere (Supplementary Figure S2.3f), implying that this shift is the result of $\mathrm{Rh}^{4+}$ reduction rather than any additional orbital contribution from La. This effect is consistent 181 with the red shift in the effective band edge observed when $\mathrm{Rh}: \mathrm{SrTiO}_{3}$ is reduced (Fig. 2a,b). 


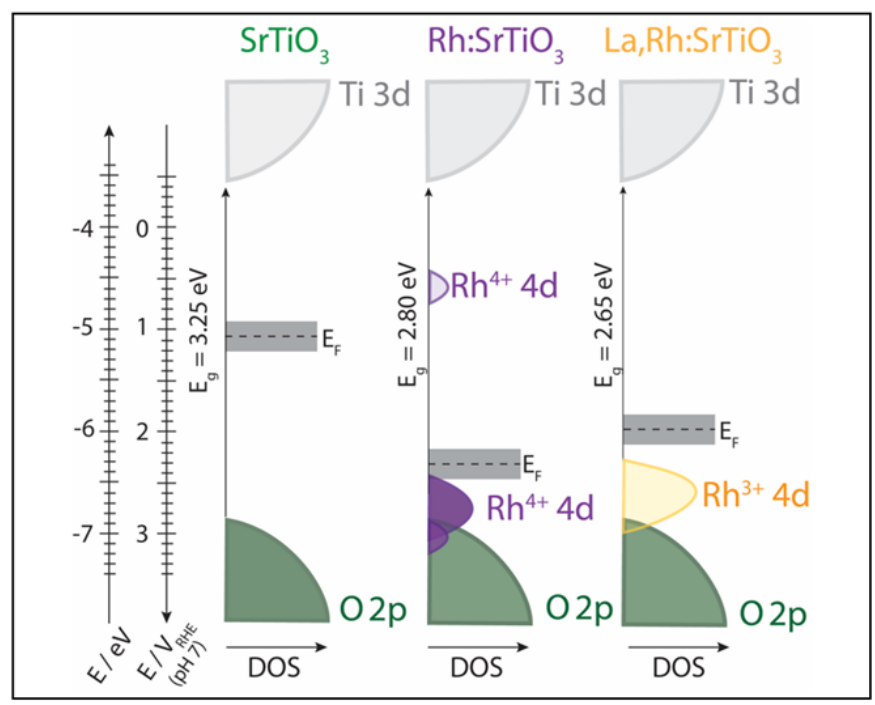

Figure 4. A simplified electronic structure model. Energy band diagrams of $\mathrm{SrTiO}_{3}, \mathrm{Rh}: \mathrm{SrTiO}_{3}$ and $\mathrm{La}_{\mathrm{SrTiO}}$ determined from the combined results of our XPS, UV-vis, (spectro)electrochemistry measurements and DFT calculations. Plotted is the density of states (DOS) on the absolute energy scale as well as on the reversible hydrogen electrode (RHE) scale at pH 7. Fermi level positions ( $E_{F}$ ) and band gap energies $\left(E_{g}\right)$ and the position of the vacant $\mathrm{Rh}^{4+}$ mid gap level in $\mathrm{Rh}: \mathrm{SrTiO}_{3}$ are also indicated. See main text for more details.

182 To verify our analysis of the VB spectra, and to provide insight into the nature of the $\mathrm{Rh}$ 183 states introduced by doping, we turned to hybrid DFT. The HSE06 functional was combined 184 with an unprecedentedly large $3 \times 3 \times 3$ supercell to enable accurate reproduction of the nominal 185 Rh-doping concentration to calculate and compare the electronic structure of doped, co-doped 186 and undoped $\mathrm{SrTiO}_{3}$ (see Methods for further details). The calculated densities of states 187 (DOS) for the VB region of $\mathrm{Rh}: \mathrm{SrTiO}_{3}$ and $\mathrm{La}, \mathrm{Rh}: \mathrm{SrTiO}_{3}$ (Fig. 3c) reveal that the broadening 188 of the VB region observed experimentally upon Rh doping is caused by the introduction of $189 \mathrm{Rh} 4 \mathrm{~d}$ states above the VB maximum and below the VB minimum of $\mathrm{SrTiO}_{3}$. Moreover, DFT 190 accurately predicts that in $\mathrm{Rh}: \mathrm{SrTiO}_{3}$, $\mathrm{Rh}$ 4d states are more deeply situated than in $\mathrm{La}, \mathrm{Rh}: \mathrm{SrTiO}_{3}$, which is verified by our experiments as detailed above (Fig. 1a and 3b). No La orbital character is observed near the band edges (Supplementary Fig. S6.1b), consistent with the concept that $\mathrm{La}^{3+}$ induces the reduction of $\mathrm{Rh}^{4+}$ via an ionic charge compensation mechanism but does not directly alter band edge composition. ${ }^{29}$ Most strikingly, a vacant mid gap state with $\mathrm{Rh} 4 \mathrm{~d}$ character is observed in $\mathrm{Rh}: \mathrm{SrTiO}_{3}$ (red arrow, Fig. 3c) which is absent in $\mathrm{La}, \mathrm{Rh}: \mathrm{SrTiO}_{3}$. As this state does not have La orbital character, and an analogous effect can be achieved by introducing an electron to $\mathrm{Rh}: \mathrm{SrTiO}_{3}$ in the presence of a compensating background charge (which localises on $\mathrm{Rh}^{4+}$ during optimisation, Supplementary Fig. S6.1d, $\mathrm{S} 6.2$ ), we attribute this change to $\mathrm{Rh}^{4+}$ reduction. Further, integration of the $\mathrm{Rh} 4 \mathrm{~d}$ DOS shows that the density of filled Rh $4 \mathrm{~d}$ states at the VB edge effectively increases by one electron upon reduction. This indicates that the $\mathrm{Rh} 4 \mathrm{~d}$ electronic structure re-arranges as an electron is added to $\mathrm{Rh}^{4+}$ and the mid gap state is incorporated into the VB (for discussion see Supplementary Fig. S6.2, S6.3).

204 Figure 4 summarises energy band diagrams of $\mathrm{SrTiO}_{3}$ and its doped equivalents determined from our SEC and DFT-supported XPS experiments. From DFT we obtain electron affinities, which are in good agreement with literature values for $\mathrm{CB}$ edge energies $\left(E_{C B}\right)$ of $\mathrm{SrTiO}_{3}{ }^{37}$ and indicate that $E_{C B}$ is largely insensitive to doping (Supplementary Fig. S6.4). As DFT calculations often slightly underestimate $E_{g}$, we use our UV-vis spectra (Fig. 1a) to position 209 the VB edge energies on an absolute energy scale, in reasonable agreement with our 210 calculated ionisation potentials (Supplementary Fig. S6.4). From VB XPS (Fig. 3a), we 
211 estimate the Fermi level position relative to the VB (in the absence of band bending) and find 212 it to be in excellent agreement with independent measurements of a very positive flatband 213 potential of $\mathrm{La}, \mathrm{Rh}: \mathrm{SrTiO}_{3}$ photocatalyst sheets $\left(+1.8 V_{R H E}\right)$ using impedance spectroscopy, 214 consistent with reported p-type character. ${ }^{24,30,31}$ Finally, we estimate the reduction potential of $215 \mathrm{Rh}^{4+}$ states using the half-wave potential obtained from SEC (Supplementary Fig. S4b) and 216 combine it with our DFT results to locate the vacant mid-gap state. 

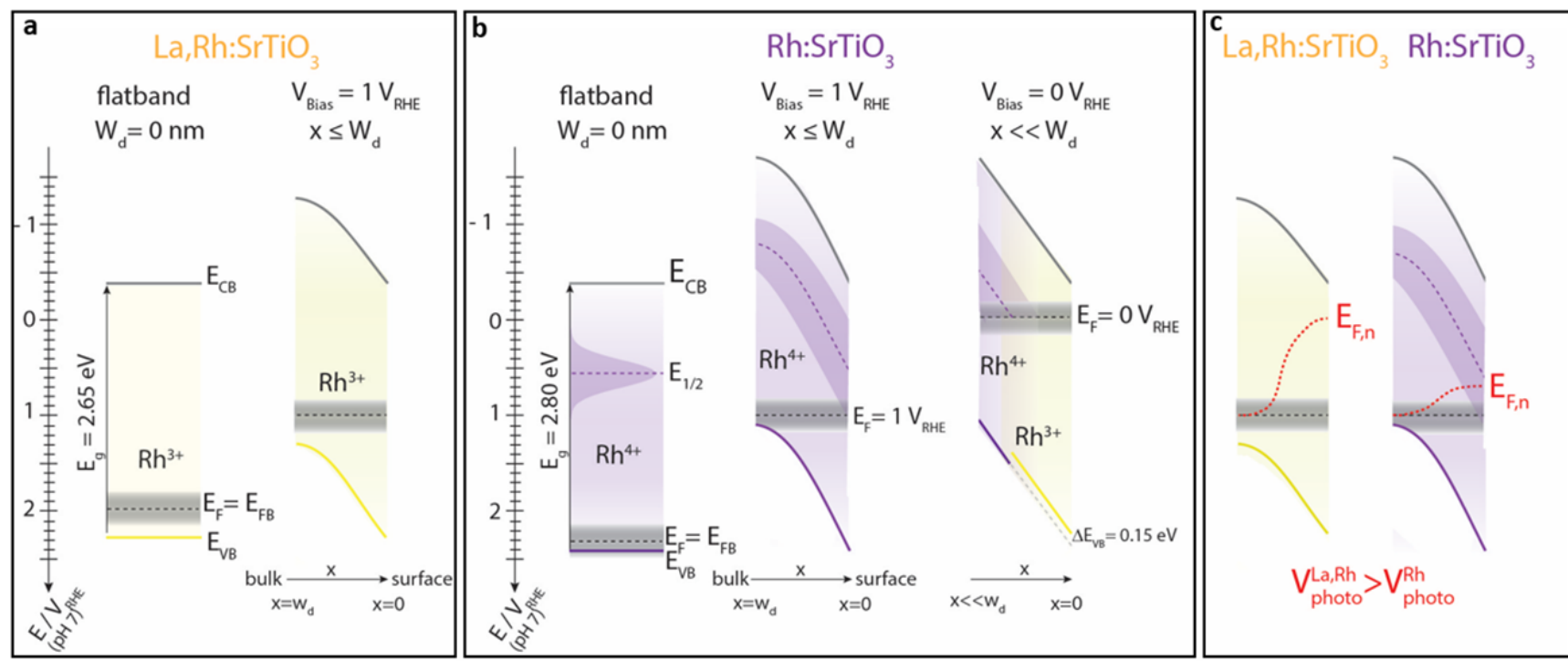

Figure 5. A simple surface depletion model explaining the in-situ charge carrier dynamics of (La,)Rh:SrTiO ${ }_{3}$ photocatalyst sheets. Model of surface depletion in $\mathrm{La}, \mathrm{Rh}: \mathrm{SrTiO}_{3}(\mathrm{a})$ and $\mathrm{Rh}: \mathrm{SrTiO}_{3}(\mathrm{~b})$ at different applied potentials in the dark. The flatband condition $\left(\mathrm{E}_{\mathrm{F}}=\mathrm{E}_{\mathrm{FB}}\right)$ for both

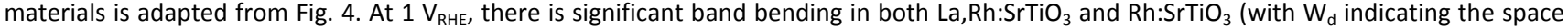
charge layer width). However, in $\mathrm{Rh}: \mathrm{SrTiO}_{3}$, the Fermi level $\left(\mathrm{E}_{\mathrm{F}}\right)$ does not exceed the reduction potential of the vacant $\mathrm{Rh}^{4+}$ level $\left(\mathrm{E}_{1 / 2}, \mathrm{purple}\right.$ dashed line), leading to Rh adopting the $4+$ oxidation state in the entire material and in the depletion layer $\left(x<W_{d}\right)$. At $0 V_{R H E}$, the energy of $\mathrm{Rh}^{4+}$ at the surface of the depletion region $\left(\mathrm{d}<<\mathrm{W}_{\mathrm{d}}\right)$ falls below the Fermi level and $\mathrm{Rh}^{4+}$ becomes reduced, leading to a re-organisation of the $\mathrm{Rh} 4 \mathrm{~d}$ states - adopting the electronic configuration of a reduced $\mathrm{Rh}: \mathrm{SrTiO}_{3}$ (indicated by yellow colouring), which is almost identical to that of $\mathrm{La}, \mathrm{Rh}: \mathrm{SrTiO}_{3}$. This is corroborated by a $0.15 \mathrm{eV}$ red-shift in the effective band gap that we observe in our SEC experiments (Fig. 2a). (c) Photovoltage build-up in $\mathrm{La}, \mathrm{Rh}: \mathrm{SrTiO}_{3}$ and $\mathrm{Rh}: \mathrm{SrTiO}_{3}$ under illumination at positive device operation potentials. Here, conduction band electrons can accumulate in $\mathrm{La}, \mathrm{Rh}: \mathrm{SrTiO}_{3}$ due to strong downward band bending leading to effective charge separation. This is indicated by a quasi-Fermi level for electrons $\left(\mathrm{E}_{\mathrm{F}, \mathrm{n}}\right)$ reaching towards the $\mathrm{CB}$. In $\mathrm{Rh}: \mathrm{SrTiO}_{3}$, a similarly strong potential drop develops at the surface, however, trapping processes likely related to the trapping of electrons by $\mathrm{Rh}^{4+}$ states prevent the accumulation of electrons, indicated by a quasi-Fermi level pinned to the $\mathrm{Rh}^{4+}$ redox potential. This in turn leads to smaller photovoltage developing in $\mathrm{Rh}: \mathrm{SrTiO}_{3}$.

217 In Figure 5, we use the energy band diagrams in Figure 4 to illustrate the expected potential218 dependence of depletion layer formation in ( $\mathrm{La}), \mathrm{Rh}: \mathrm{SrTiO}_{3}$, and relate these to our potential219 dependent SEC, PIA and TA measurements (Fig. 2). A striking result of this analysis is that 220 in both $\mathrm{La}, \mathrm{Rh}: \mathrm{SrTiO}_{3}$ (Fig. 5a) and $\mathrm{Rh}: \mathrm{SrTiO}_{3}$ (Fig. 5b), a strong potential drop at the semiconductor-electrolyte liquid junction is created even at the most positive potentials studied (e.g. $1 V_{R H E}$ ) due to their strongly positive flatband potentials (Fig 4). The field in the depletion region at these potentials appears to be sufficient to efficiently separate charge in $\mathrm{La}, \mathrm{Rh}: \mathrm{SrTiO}_{3}$, as inducing a further volt of band bending (i.e. at $0 V_{R H E}$ ) yields only a modest increase in the photogeneration of long-lived CB electrons under operational conditions (Fig. 2e). This implies that the downward shift in flatland potentials induced by Rh doping drives effective charge separation even at positive applied potentials. This is consistent with the remarkably early onset potentials (up to $1.2 \mathrm{~V}_{\mathrm{RHE}}$ ) previously observed in photocatalyst sheet half-electrodes. ${ }^{25}$ However, despite a similar flatband potential to La, Rh:SrTiO 3 , Rh:SrTiO is unable to photogenerate long-lived electrons at equivalent positive potentials (i.e. $1 V_{R H E}$ ). Instead, $\mathrm{Rh}: \mathrm{SrTiO}_{3}$ shows a yield of $\mathrm{CB}$ electrons which tracks the redox wave originating from $\mathrm{Rh}^{4+}$ reduction (Fig. 2f, Supplementary Fig. S4b), with the largest changes occurring around $\mathrm{E}_{1 / 2}$ of the $\mathrm{Rh}^{4+} / \mathrm{Rh}^{3+}$ redox couple. Only at potentials negative of this redox potential do the yields and lifetimes of $\mathrm{CB}$ electrons in $\mathrm{Rh}: \mathrm{SrTiO}_{3}$ and $\mathrm{La}, \mathrm{Rh}: \mathrm{SrTiO}_{3}$ converge. In Figure $5 \mathrm{c}$ we use our model to explain this behaviour. At potentials positive of $\mathrm{E}_{1 / 2}$, minority carriers in $\mathrm{Rh}: \mathrm{SrTiO}_{3}$ are trapped and recombine via mid-gap $\mathrm{Rh}^{4+}$ states. The quasi-Fermi level of electrons $\left(\mathrm{E}_{\mathrm{F}, \mathrm{n}}\right)$ is therefore likely to be pinned to these mid-gap states, leading to a diminished photovoltage in comparison to $\mathrm{La}, \mathrm{Rh}: \mathrm{SrTiO}_{3}$ (Supplementary Fig. 7). At 


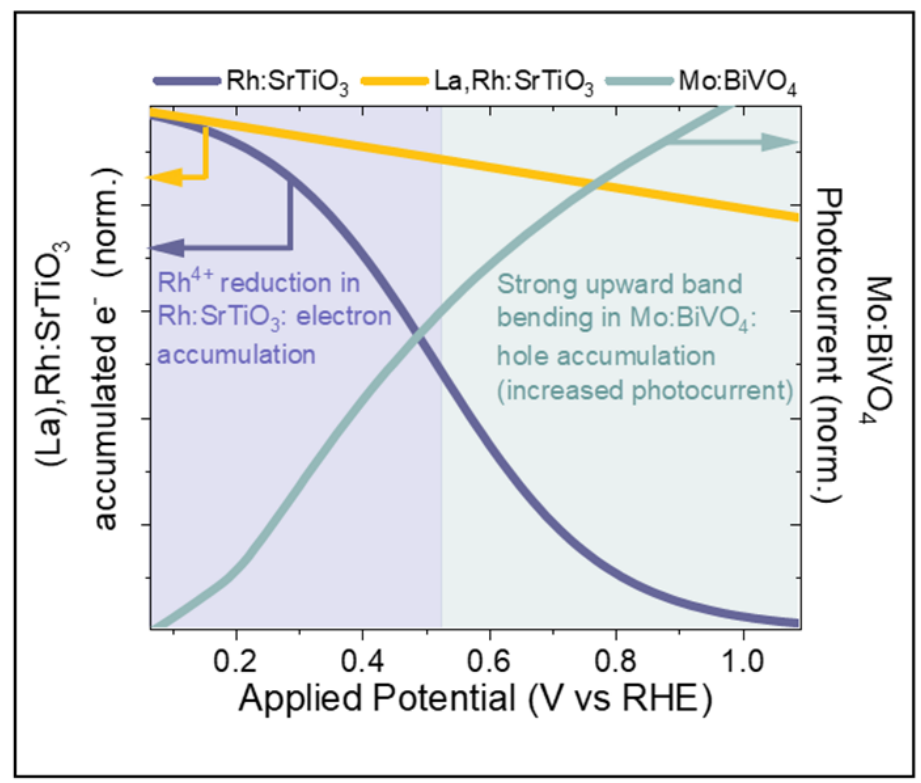

Figure 6. The role of Rh oxidation state and La co-doping in determining the performance of a Mo:BiVO ${ }_{4} /\left(\mathrm{La}_{)}\right), \mathrm{Rh}_{\mathrm{SrTiO}} \mathrm{Z}$-scheme device. Electron accumulation under operational conditions in (La), $\mathrm{Rh}: \mathrm{SrTiO}_{3}$ (Fig. 2f) plotted alongside a normalised J-V curve for typical Mo:BiVO ${ }_{4}$ photocatalyst sheets in the presence of a Fe/Ni based co-catalyst. ${ }^{17}$

potentials negative of $\mathrm{E}_{1 / 2}, \mathrm{Rh}^{4+}$ states in the depletion layer are reduced, and persistent $\mathrm{CB}$ electrons are observed (Fig. 2d). Hence, La co-doping can be understood as obviating the need for the strong negative potentials $\left(<<0.52 \mathrm{~V}_{R H E}\right)$ or chemically reducing conditions $^{23,25,27,38}$ that would be otherwise required to reduce surface $\mathrm{Rh}^{4+}$ states. This suppresses electron trapping, leading to the build-up of a higher photovoltage due to the accumulation of minority carriers on timescales of the water splitting reaction.

Due to current matching requirements, the operation of complete photocatalyst sheet devices is thus also $\mathrm{Rh}$ oxidation state dependent. Hence, in a $\mathrm{Rh}: \mathrm{SrTiO}_{3} / \mathrm{Mo}: \mathrm{BiVO}_{4}$ device, large yields of persistent electrons in $\mathrm{Rh}: \mathrm{SrTiO}_{3}$ can solely be obtained closer to the flatband potential of $\mathrm{Mo}: \mathrm{BiVO}_{4}$ (ca. $0.1 \mathrm{~V}_{R H E}{ }^{39}$ ) or, in other words, close to the onset of photocurrent for an optimal Mo:BiVO 4 photoanode. ${ }^{40,41}$ In contrast, in a $\mathrm{La}, \mathrm{Rh}: \mathrm{SrTiO}_{3} / \mathrm{Mo}: \mathrm{BiVO}_{4}$ device, $250 \mathrm{La}$ fixes the $\mathrm{Rh}$ oxidation state to $\mathrm{Rh}^{3+}$ and removes the $\mathrm{Rh}^{4+}$ mid-gap level without compromising the position of the Fermi level. This leads to accumulation of $\mathrm{CB}$ electrons even at remarkably positive potentials. This is illustrated in Figure 6 where the population of accumulated $\mathrm{CB}$ electrons in (La), $\mathrm{Rh}: \mathrm{SrTiO}_{3}$ sheets (taken from Fig. 2f) is plotted alongside a JV curve of a previously reported typical $\mathrm{Mo}: \mathrm{BiVO}_{4}$ photocatalyst sheet half electrode. ${ }^{17}$ Figure 6 predicts that the crossing point of $\mathrm{Rh}: \mathrm{SrTiO}_{3} / \mathrm{Mo}: \mathrm{BiVO}_{4}$ device would be at more negative potentials, where the $\mathrm{Rh}: \mathrm{SrTiO}_{3}$ surface is only partially reduced and the predicted photocurrent low. On the other hand, a $\mathrm{La}, \mathrm{Rh}: \mathrm{SrTiO}_{3} / \mathrm{Mo}: \mathrm{BiVO}_{4}$ crosses at a significantly more positive potential, at which photogeneration of long-lived charge carriers is high in both Mo:BiVO ${ }_{4}$ and $\mathrm{La}, \mathrm{Rh}: \mathrm{SrTiO}_{3}$, enabling both efficient proton reduction and water oxidation.

260 The more positive crossing point of the respective half-cell J-E curves in turn leads to a Z261 scheme photocatalyst sheet device requiring a metal contact with a high work function (i.e. $\mathrm{Au}$ ), consistent with calculations in the work of Wang et al. ${ }^{26}$ The carrier dynamics of this interface are of significant interest. However, the surface selective nature of the measurements presented here preclude study of the back contact.

265 It is remarkable that chemical reduction of $\mathrm{Rh}: \mathrm{SrTiO}_{3}$ does not compromise the position of 266 the Fermi level as would be expected from simply considering the filling of the $\mathrm{Rh}^{4+}$ mid gap 267 level upon reduction in the absence of any reorganization. We therefore consider the 
268 oxidation state dependent $\mathrm{Rh} 4 \mathrm{~d}$ electronic structure to be a crucial and distinguishing 269 operational parameter in this material, as conservation of the position of the Fermi level upon chemical reduction leads to extremely positive flatband potentials being observed in the $\mathrm{Rh}$ doped and $\mathrm{La}, \mathrm{Rh}$ co-doped materials alike. This drives strong band bending at the semiconductor/electrolyte interface in-situ, meaning that charge separation is limited by density of the vacant mid gap levels associated only with $\mathrm{Rh}^{4+}$ rather than the strength or width of the depletion layer. Thus, co-doping with La reduces $\mathrm{Rh}^{4+}$; removing mid gap levels without strongly influencing band bending. This drives a positive shift in the crossing point of the complete Z-scheme device towards a crossing point where both water oxidation and proton reduction occurs efficiently.

In conclusion, by linking charge accumulation to electronic structure in (La), $\mathrm{Rh}: \mathrm{SrTiO}_{3}$ we are able to explain the record device operation of the $\mathrm{La}, \mathrm{Rh}: \mathrm{SrTiO}_{3} / \mathrm{Mo}: \mathrm{BiVO}_{4}$ photocatalyst sheets. We find that $\mathrm{Rh}$ doping narrows the effective optical gap of $\mathrm{SrTiO}_{3}$ and induces a strong downward shift in flatband potential, successfully creating a p-type visible light absorber. Using Rh alone to dope the wide band gap absorber produces a vacant mid-gap $\mathrm{Rh}$ $4 \mathrm{~d}$ state. During illumination, this state prevents the accumulation of electrons near the conduction band and instead promotes charge trapping and recombination. Reduction of $\mathrm{Rh}^{4+}$ leads to a reorganization of $\mathrm{Rh} 4 \mathrm{~d}$ orbitals, integrating this state into the valence band region. While the reduction to $\mathrm{Rh}^{3+}$ can be driven by negative applied potential or by a reductive annealing treatment, co-doping with La appears to be an elegant strategy to effectively and persistently mitigate the formation of the mid-gap state without compromising p-type character. In the absence of a mid-gap state, the strongly positive flatband potential of $\mathrm{La}, \mathrm{Rh}: \mathrm{SrTiO}_{3}$ enables strong downward band bending even under relatively positive potentials (e.g. $+1 \mathrm{~V}_{\mathrm{RHE}}$ ), enabling bipolar charge accumulation in the device at potentials where both the $\mathrm{n}$ - and $\mathrm{p}$-type semiconductors separate charge efficiently.

More broadly, this work identifies both electronic structure reorganisation and Fermi level effects as key parameters that must be considered in engineering novel functional visible light absorbing materials for photocatalysis. The insights gained herein lead to a deeper understanding of the interplay between electronic structure, dopant oxidation states, minority carrier lifetimes and device operation in cutting edge photocatalyst devices. Having identified the crucial role of co-doping in the function of the complete Z-scheme device, we note that a necessary prerequisite to succeeding in creating new band gap engineered visible light absorbers may be the choice of a perovskite $\left(\mathrm{ABX}_{3}\right)$ host lattice, such as $\mathrm{SrTiO}_{3}$, where two cation sites can be substituted independently of one another in a crystal lattice that is structurally tolerant to doping. This represents a crucial break from studies on $\mathrm{TiO}_{2}$, where only one cation site can be substituted in a lattice that is itself less tolerant to doping. ${ }^{36}$

\section{Acknowledgements}

B.M thanks the EPSRC for a doctoral training partnership and the UK Solar Fuels Network for an exchange scholarship to the group of K.D. BM also thanks Prof. Rob Palgrave for discussion of his previous work on $\mathrm{Rh}$ doped $\mathrm{TiO}_{2}$ and doped oxides and D.H.K Murthy for advice on sample choice and handling. S.S thanks the EPSRC for a doctoral training partnership. L.S. and J. R. D. acknowledge funding from the European Research Council (H2020-MSCA-IF-2016, Grant No. 749231 and AdG Intersolar, Grant No. 291482, respectively). Funding was also obtained from the Artificial Photosynthesis Project of the New Energy and Industrial Technology Development Organization. AR acknowledges the support from the Analytical Chemistry Trust Fund for her CAMS-UK Fellowship and from Imperial College London for her Imperial College Research Fellowship. K.D thanks the Artificial Photosynthesis Project of the New Energy and Industrial Technology Development Organization (NEDO) for support. R. G. thanks the Natural Sciences and Engineering 
318 Research Council of Canada (NSERC) for operational funding (Grant No. RGPIN-2019-

319 05521). A. K. thanks Imperial College for a Junior Research Fellowship, the EPSRC for a

320 Capital Award Emphasising Support for Early Career Researchers and the Royal Society for

321 an Equipment Grant (RSG\R1\180434)

322 Author Contributions

323 B.M. carried out all optical, SEM and XPS measurements and wrote the manuscript with help 324 from L.S. and S.S. XPS measurements and interpretation of results were supervised by A.R. 325 and D.J.P. Q.W. synthesised all materials, fabricated all devices and performed XRD. K.T.B. 326 performed all calculations of doped, co-doped and undoped STO, with the exception of the 327 DFT study of Rh doping concentration, which was performed by R.G.C. L.S supervised this 328 work, guided SEM, EDX and spectroelectrochemical measurements, oversaw data 329 interpretation and manuscript preparation, and conceptualised Figures 4, 5 and 6. R.G. and 330 A.K. trained B.M. and supervised optical measurements. T.H. co-supervised this work and 331 K.D. and J.R.D. directed the research. All authors commented on the manuscript.

332 Corresponding author

333 Correspondence to Dr Ludmilla Steier. 1.steier@imperial.ac.uk

334 Competing interests

335 The authors declare no competing interests.

336 Data Availability

337 The data presented in the main body of this paper is available in csv format on Zenodo at 338 http://doi.org/10.5281/zenodo.4063942 and source data is available in opj format also on 339 Zenodo at http://doi.org/10.5281/zenodo.4071556. Both can be used under the Creative 340 Commons Attribution licence 4.0. 
Synthesis of Rh and La,Rh:SrTiO ${ }_{3}: \mathrm{Rh}: \mathrm{SrTiO}_{3}$ and $\mathrm{La}, \mathrm{Rh}: \mathrm{SrTiO}_{3}$ were synthesised by a previously reported two step solid state reaction. ${ }^{25,42}$ In the first step, rutile $\mathrm{TiO}_{2}$ (Kanto Chemicals, 99.0\%) and $\mathrm{SrCO}_{3}$ (Kanto Chemicals, $99.9 \%$, calcined in air at $573 \mathrm{~K}$ for $1 \mathrm{~h}$ ) were ground in a mortar to obtain a mixture with a $\mathrm{Sr} / \mathrm{Ti}$ ratio of 1.05 . The mixture was then calcined at $1423 \mathrm{~K}$ for $10 \mathrm{~h}$ to produce $\mathrm{SrTiO}_{3}$. In the second step, $\mathrm{SrTiO}_{3}$ was ground in ethanol with $\mathrm{Rh}_{2} \mathrm{O}_{3}$ (Kanto Chemicals, 99.9\%) and calcined at $1373 \mathrm{~K}$ for $6 \mathrm{~h}$ to make $\mathrm{Rh}: \mathrm{SrTiO}_{3}$. For $\mathrm{La}, \mathrm{Rh}: \mathrm{SrTiO}_{3}$ fabrication, both $\mathrm{La}_{2} \mathrm{O}_{3}$ (Kanto Chemicals, $99.99 \%$, freshly calcined in air at $1273 \mathrm{~K}$ for $12 \mathrm{~h}$ ) and $\mathrm{Rh}_{2} \mathrm{O}_{3}$ (Kanto Chemicals, 99.9\%) were calcined at $1373 \mathrm{~K}$ for $6 \mathrm{~h}$. In both cases, $\mathrm{La}$ and $\mathrm{Rh}$ was added such that the nominal doping concentration (i.e $[\mathrm{Rh}] /\left([\mathrm{Rh}]+[\mathrm{Ti}]\right.$ or $[\mathrm{La}] /([\mathrm{La}]+[\mathrm{Sr}])$ was $4 \mathrm{~mol} \% . \mathrm{H}_{2}-\mathrm{Rh}: \mathrm{SrTiO}_{3}$ was produced by annealing $\mathrm{Rh}: \mathrm{SrTiO}_{3}$ powder at $573 \mathrm{~K}$ in a hydrogen atmosphere for two hours. For transient absorption scavenger studies, films were fabricated directly from powders by dispersing $50 \mathrm{mg}$ of powder in water, drop casting on to glass and calcining at $673 \mathrm{~K}$ for $1 \mathrm{~h}$.

Fabrication of photocatalyst sheets: (La), $\mathrm{Rh}: \mathrm{SrTiO}_{3}$ photocatalyst sheets were fabricated by a modified particle transfer method. The procedure was identical to previous reports except that Mo:BiVO 4 particles were omitted and a much thicker Au layer (ca. $2 \mu \mathrm{m}$ as opposed to ca. $350 \mathrm{~nm}$ ) was used to create a continuously conductive back contact. Doped $\mathrm{SrTiO}_{3}(20 \mathrm{mg})$ was suspended in isopropanol $(99.9 \%, 0.5 \mathrm{ml})$, drop-cast on a glass substrate $\left(3 \times 3 \mathrm{~cm}^{2}\right)$ and left to dry at room temperature overnight. The Au back contact was then deposited by thermal vacuum evaporation (VFR-200M/ERH, ULVAC KIKO) at an evaporation rate of approximately $20 \mathrm{~nm} \mathrm{~s}^{-1}$ at a base pressure of $2.6 \times 10^{-3} \mathrm{~Pa}$. The exposed Au surface was then bonded to a second glass plate $\left(3 \times 3 \mathrm{~cm}^{2}\right)$ with double sided carbon tape and lifted off the primary glass plate. The resulting photocatalyst sheet was then ultrasonicated twice in distilled water for 2 minutes to remove any unattached particles.

Scanning electron microscopy (SEM): SEM images were taken on a LEO GEMINI 1525 microscope using a $1.5 \mathrm{keV}$ electron beam and a secondary electron detector. As the back Au contact in the photocatalyst sheets provides a highly conductive pathway for charge, no conductive coating was required. EDX was performed on the same instrument using an Oxford Instruments X-act detector at a beam voltage of $20 \mathrm{keV}$ and a $60 \mathrm{~mm}$ aperture.

X-ray photoelectron spectroscopy (XPS): XPS was performed on a Thermo Scientific K-alpha+ instrument. Powdered samples were attached to a stainless-steel plate using conductive carbon tape. The instrument uses monochromated and microfocused $\mathrm{Al} \mathrm{K \alpha}(\mathrm{h} v=1486.6 \mathrm{eV})$ radiation to eject photoelectrons which are then analysed using a $180^{\circ}$ double-focusing hemispherical analyser with a 2D detector. Spectra were collected at $2 \times 10^{-9}$ mbar base pressure. A flood gun was used to minimize sample charging. All samples were referenced against the C-C peak of adventitious carbon in the $\mathrm{C} 1 \mathrm{~s}$ spectrum at a binding energy of $284.8 \mathrm{eV}$ to correct for any charge that is not neutralised by the flood gun. Further effects were then accounted for by taking the separation from the $\mathrm{O} 1 \mathrm{~s}$ oxide peak. Data was analysed using the CASA XPS package.

Ultraviolet-visible absorption spectroscopy and spectroelectrochemistry: Reflectance spectra of the photocatalyst sheets were collected using a Shimadzu UV-vis 2600 spectrophotometer equipped with an integrating sphere, using a disk of pressed barium sulphate as a $100 \%$ reflecting reference. The resulting diffuse reflectance spectra were then converted to a unit proportional to absorptance using the Kubelka-Munk function, $F(R)=\frac{k}{s}=\frac{(1-R)^{2}}{(2 R)}$. Where $k$ and $s$ respectively correspond to absorption and scattering coefficients and $R$ corresponds to the reflectance (the fraction of light reflected in comparison to the fully scattering $\mathrm{BaSO}_{4}$ reference). For spectroelectrochemical measurements, photocatalyst sheets were measured in a quartz cuvette in three-electrode configuration using an $\mathrm{Ag} / \mathrm{AgCl}$ (sat'd $\mathrm{KCl}$ ) reference electrode, a platinum mesh counter electrode and the doped $\mathrm{SrTiO}_{3}$ working electrodes in $0.1 \mathrm{M} \mathrm{Na}_{2} \mathrm{SO}_{4}$ electrolyte (pH 7). Potentials were applied using a Metrohm Autolab PGSTAT 101 potentiostat. Reflection and refraction from the cuvette do not change with applied potential and so did not contribute to the observed change in the Kubelka- 
Munk function. A small offset at $820 \mathrm{~nm}$ is visible due to a change in detector and a low background

394 level of reflected light in this experiment.

395 Hybrid Density functional calculations: All calculations are performed using the VASP package. ${ }^{43}$

396 For doping calculations a $3 \times 3 \times 3$ supercell was created. In the case of co-doping all symmetry

397 inequivalent positions of the dopants were explored, although no qualitative and very little

398 quantitative differences were found. We therefore use a single configuration for presenting our results.

399 For relaxation of atomic positions the PBEsol functional ${ }^{44}$, projector augmented pseudopotentials ${ }^{45}$,

400 and a cut-off energy of $500 \mathrm{eV}$, with k-point sampling defined as an evenly spaced grid in reciprocal

401 space with a density scaled to the unit cell size were used to achieve uniform sampling with a target

402 length cut-off of $10 \AA$, as described by Moreno and Soler ${ }^{46}$. The relaxed structures were then used for

403 input to hybrid DFT calculations using the HSE06 functional ${ }^{44}$ to calculate accurate electronic

404 structure.

405 Diffuse reflectance transient absorption and photoinduced absorption: Transient absorption and

406 photoinduced absorption measurements were carried out on a home built setup described in our

407 previous publications. ${ }^{47}$ Briefly, micro-second to second transient absorption decays were acquired by

408 measuring the diffuse reflectance of the opaque samples studied herein. A Nd:YAG laser (OPOTEK

409 Opolette $355 \mathrm{II}, 7 \mathrm{~ns}$ pulse width) was used as the excitation source, producing $355 \mathrm{~nm}$ light that was

410 transmitted to the sample using a liquid light guide. An excitation power density of $400 \mu \mathrm{J} / \mathrm{cm}^{2}$ was

411 typically used in conjunction with a laser repetition rate of $0.8 \mathrm{~Hz}$. Probe light was generated by a

$412100 \mathrm{~W}$ Bentham IL1 quartz halogen lamp. Long pass filters (Comar Instruments) and an IR filter

$413\left(\mathrm{H}_{2} \mathrm{O}, 5 \mathrm{~cm}\right.$ path length) were positioned between the lamp and sample to minimise short wavelength

414 irradiation and heating of the sample. Diffuse reflectance from the sample was collected and relayed

415 to a monochromator (Oriel Cornerstone 130) through a long pass filter to select the probe wavelength.

416 Acquisitions were triggered by a photodiode (Thorlabs DET10A) exposed to laser scatter. A Si

417 photodiode (Hamamatsu S3071) was used as a detector in the visible region and an InGaAs diode

418 (Hamamatsu G10899-03K) in the near IR. Data at times faster than $2 \mathrm{~ms}$ were amplified by custom

419 electronics and recorded by an oscilloscope (Tektronics DPO3012) while data slower than 2 ms was

420 simultaneously recorded on a National Instrument DAQ card (NI USB-6251). Kinetic traces were

421 typically obtained from the average of 100 laser pulses. Data was acquired and processed using

422 software written in the LabVIEW environment (Austin Consultants). Photoinduced absorption data,

423 were collected with the same setup replacing the laser pulse by a continuous wave illumination of a

$424365 \mathrm{~nm}$ LED at an intensity of $8 \mathrm{~mW} \mathrm{~cm}^{-2}$, corresponding to $1 / 2$ sun of absorbed photons assuming a

425 sharp absorption edge at $470 \mathrm{~nm}$. The percentage change in reflectance was calculated according to

426 pioneering work by Wilkinson and co-workers. ${ }^{48}$ Here the fractional change in reflected light due to

427 transient absorption is:

428

429 Where $V_{0}$ is the voltage arising on Si photodiode from the probe beam before the pump, $V_{t}$ is the

$$
R_{t}=\frac{V_{t}-V_{0}}{V_{0}}
$$

voltage on the diode at time $t$ after the pump. The $\%$ change in absorption (\% Abs.) is thus:

436

437

438

$$
\% A b s=\left(1-R_{t}\right) \cdot 100
$$

The changes of reflectance observed were low, with the largest signals being on the order of $1 \%$. This enabled the transient signal to be taken as directly proportional to the concentration of excited state species. ${ }^{49}$

\section{References}


439 1. Fujishima, A., Zhang, X. \& Tryk, D. A. TiO2 photocatalysis and related surface

2. $\quad$ Pai, Y. Y., Tylan-Tyler, A., Irvin, P. \& Levy, J. Physics of SrTiO3 - based heterostructures and nanostructures: A review. Reports on Progress in Physics vol. 81 (2018).

3. Goto, Y. et al. A Particulate Photocatalyst Water-Splitting Panel for Large-Scale Solar Hydrogen Generation. Joule 2, 509-520 (2018).

4. Zhao, Z. et al. Electronic structure basis for enhanced overall water splitting photocatalysis with aluminum doped $\mathrm{SrTiO}_{3}$ in natural sunlight. Energy Environ. Sci. 12, 1385-1395 (2019).

5. Abe, R. Recent progress on photocatalytic and photoelectrochemical water splitting under visible light irradiation. J. Photochem. Photobiol. C Photochem. Rev. 11, 179209 (2011).

6. Khan, S. U. M., Al-Shahry, M. \& Ingler, W. B. Efficient photochemical water splitting by a chemically modified n-TiO2. Science (80-. ). 297, 2243-2245 (2002).

7. Asahi, R., Morikawa, T., Ohwaki, T., Aoki, K. \& Taga, Y. Visible-light photocatalysis in nitrogen-doped titanium oxides. Science (80-. ). 293, 269-271 (2001).

8. Konta, R., Ishii, T., Kato, H. \& Kudo, A. Photocatalytic activities of noble metal ion doped SrTiO3 under visible light irradiation. J. Phys. Chem. B 108, 8992-8995 (2004).

9. Herrmann, J. M., Disdier, J. \& Pichat, P. Effect of chromium doping on the electrical and catalytic properties of powder titania under UV and visible illumination. Chem. Phys. Lett. 108, 618-622 (1984).

10. Daghrir, R., Drogui, P. \& Robert, D. Modified $\mathrm{TiO}_{2}$ for environmental photocatalytic applications: A review. Ind. Eng. Chem. Res. 52, 3581-3599 (2013).

11. Sakatani, Y. et al. Metal ion and $\mathrm{N}$ co-doped $\mathrm{TiO}_{2}$ as a visible-light photocatalyst. $J$. Mater. Res. 19, 2100-2108 (2004).

12. Kudo, A., Niishiro, R., Iwase, A. \& Kato, H. Effects of doping of metal cations on morphology, activity, and visible light response of photocatalysts. Chem. Phys. 339, 104-110 (2007).

13. Torres, G. R., Lindgren, T., Lu, J., Granqvist, C. G. \& Lindquist, S. E. Photoelectrochemical study of nitrogen-doped titanium dioxide for water oxidation. $J$. Phys. Chem. B 108, 5995-6003 (2004).

14. Sivula, K. \& Van De Krol, R. Semiconducting materials for photoelectrochemical energy conversion. Nat. Rev. Mater. 1, 15010 (2016).

15. Tilley, S. D., Cornuz, M., Sivula, K. \& Grätzel, M. Light-inducedwater splitting with hematite: Improved nanostructure and iridium oxide catalysis. Angew. Chemie - Int. Ed. 49, 6405-6408 (2010).

16. Zhong, D. K. \& Gamelin, D. R. Photo-electrochemical water oxidation by cobalt catalyst ('Co-Pi') $/ \alpha-\mathrm{Fe}_{2} \mathrm{O}_{3}$ composite photoanodes: Oxygen evolution and resolution of a kinetic bottleneck. J. Am. Chem. Soc. 132, 4202-4207 (2010).

17. Kuang, Y. et al. Ultrastable low-bias water splitting photoanodes via photocorrosion inhibition and in situ catalyst regeneration. Nat. Energy 2, 16191 (2017).

18. Kim, J. H. et al. Awakening Solar Water Splitting Activity of ZnFe2O4 Nanorods by Hybrid Microwave Annealing. Adv. Energy Mater. 5, 1401933 (2015).

19. Li, Y. et al. Cobalt phosphate-modified barium-doped tantalum nitride nanorod photoanode with $1.5 \%$ solar energy conversion efficiency. Nat. Commun. 4, 2566 (2013).

20. Minegishi, T., Nishimura, N., Kubota, J. \& Domen, K. Photoelectrochemical properties of $\mathrm{LaTiO}_{2} \mathrm{~N}$ electrodes prepared by particle transfer for sunlight-driven water splitting. Chem. Sci. 4, 1120-1124 (2013). 
21. Maeda, K. et al. Photocatalyst releasing hydrogen from water. Nature 440, 295 (2006).

22. Luo, J. et al. $\mathrm{Cu}_{2} \mathrm{O}$ Nanowire Photocathodes for Efficient and Durable Solar Water Splitting. Nano Lett. 16, 1848-1857 (2016).

23. Wang, Q., Hisatomi, T., Ma, S. S. K., Li, Y. \& Domen, K. Core/shell structured Laand Rh-Codoped $\mathrm{SrTiO} 3$ as a hydrogen evolution photocatalyst in Z-scheme overall water splitting under visible light irradiation. Chem. Mater. 26, 4144-4150 (2014).

24. Wang, Q. et al. Z-scheme water splitting using particulate semiconductors immobilized onto metal layers for efficient electron relay. J. Catal. 328, 308-315 (2015).

25. Wang, Q. et al. Scalable water splitting on particulate photocatalyst sheets with a solar-to-hydrogen energy conversion efficiency exceeding 1\%. Nat. Mater. 15, 611615 (2016).

26. Wang, Q. et al. Particulate photocatalyst sheets based on carbon conductor layer for efficient Z-scheme pure-water splitting at ambient pressure. J. Am. Chem. Soc. 139, 1675-1683 (2017).

27. Kawasaki, S. et al. Elucidation of Rh-induced In-gap states of $\mathrm{Rh}: \mathrm{SrTiO}_{3}$ visible-lightdriven photocatalyst by soft X-ray spectroscopy and first-principles calculations. $J$. Phys. Chem. C 116, 24445-24448 (2012).

28. Abe, Y., Kato, K., Kawamura, M. \& Sasaki, K. Rhodium and Rhodium Oxide Thin Films Characterized by XPS. Surf. Sci. Spectra 8, 117-125 (2001).

29. Modak, B. \& Ghosh, S. K. Exploring the Role of La Codoping beyond Charge Compensation for Enhanced Hydrogen Evolution by Rh-SrTiO3. J. Phys. Chem. B 119, 11089-11098 (2015).

30. Murthy, D. H. K. et al. Revealing the role of the Rh valence state, la doping level and $\mathrm{Ru}$ cocatalyst in determining the $\mathrm{H}_{2}$ evolution efficiency in doped $\mathrm{SrTiO}_{3}$ photocatalysts. Sustain. Energy Fuels 3, 208-218 (2019).

31. Iwashina, K. \& Kudo, A. Rh-doped $\mathrm{SrTiO}_{3}$ photocatalyst electrode showing cathodic photocurrent for water splitting under visible-light irradiation. J. Am. Chem. Soc. 133, 13272-13275 (2011).

32. Godin, R., Kafizas, A. \& Durrant, J. R. Electron transfer dynamics in fuel producing photosystems. Current Opinion in Electrochemistry vol. 2 136-143 (2017).

33. Murthy, D. H. K. et al. Revealing the role of the Rh valence state, la doping level and $\mathrm{Ru}$ cocatalyst in determining the $\mathrm{H} 2$ evolution efficiency in doped SrTiO 3 photocatalysts. Sustain. Energy Fuels 3, 208-218 (2019).

34. Iwashina, K. \& Kudo, A. Rh-doped $\mathrm{SrTiO} 3$ photocatalyst electrode showing cathodic photocurrent for water splitting under visible-light irradiation. J. Am. Chem. Soc. 133, 13272-13275 (2011).

35. Oropeza, F. E. \& Egdell, R. G. Control of valence states in Rh-doped TiO2 by Sb codoping: A study by high resolution X-ray photoemission spectroscopy. Chem. Phys. Lett. 515, 249-253 (2011).

36. Glover, E. N. K., Ellington, S. G., Sankar, G. \& Palgrave, R. G. The nature and effects of rhodium and antimony dopants on the electronic structure of TiO2: Towards design of Z-scheme photocatalysts. J. Mater. Chem. A 4, 6946-6954 (2016).

37. Fujisawa, J. ichi, Eda, T. \& Hanaya, M. Comparative study of conduction-band and valence-band edges of $\mathrm{TiO}_{2}, \mathrm{SrTiO}_{3}$, and $\mathrm{BaTiO}_{2}$ by ionization potential measurements. Chem. Phys. Lett. 685, 23-26 (2017).

38. Kawasaki, S. et al. Epitaxial Rh-doped SrTiO3 thin film photocathode for water splitting under visible light irradiation. Appl. Phys. Lett. 101, 033910 (2012).

39. Rettie, A. J. E. et al. Combined charge carrier transport and photoelectrochemical characterization of BiVO4 single crystals: Intrinsic behavior of a complex metal oxide. 
J. Am. Chem. Soc. 135, 11389-11396 (2013).

40. Ma, Y., Le Formal, F., Kafizas, A., Pendlebury, S. R. \& Durrant, J. R. Efficient suppression of back electron/hole recombination in cobalt phosphate surface-modified undoped bismuth vanadate photoanodes. J. Mater. Chem. A 3, 20649-20657 (2015).

41. Zachäus, C., Abdi, F. F., Peter, L. M. \& Van De Krol, R. Photocurrent of BiVO4 is limited by surface recombination, not surface catalysis. Chem. Sci. 8, 3712-3719 (2017).

42. Wang, Q. et al. Particulate photocatalyst sheets based on carbon conductor layer for efficient Z-scheme pure-water splitting at ambient pressure. J. Am. Chem. Soc. 139, 1675-1683 (2017).

43. Joubert, D. From ultrasoft pseudopotentials to the projector augmented-wave method. Physical Review B - Condensed Matter and Materials Physics vol. 59 (1999).

44. Perdew, J. P. et al. Generalized gradient approximation for solids and their surfaces. (2007) doi:10.1103/PhysRevLett.100.136406.

45. Kresse, G. \& Furthmüller, J. Efficient iterative schemes for ab initio total-energy calculations using a plane-wave basis set. Phys. Rev. B - Condens. Matter Mater. Phys. 54, 11169-11186 (1996).

46. Moreno, J. \& Soler, J. M. Optimal meshes for integrals in real- and reciprocal-space unit cells. Phys. Rev. B 45, 13891-13898 (1992).

47. Godin, R., Wang, Y., Zwijnenburg, M. A., Tang, J. \& Durrant, J. R. Time-Resolved Spectroscopic Investigation of Charge Trapping in Carbon Nitrides Photocatalysts for Hydrogen Generation. J. Am. Chem. Soc. 139, 5216-5224 (2017).

48. Wilkinson, F. Diffuse reflectance laser flash photolysis. J. Photochem. 17, 52 (1981).

49. Kessler, R. W., Oelkrug, D. \& Wilkinson, F. The Detection of Transient Spectra within Polycrystalline Samples Using the New Technique of Diffuse Reflectance Flash Photolysis. 

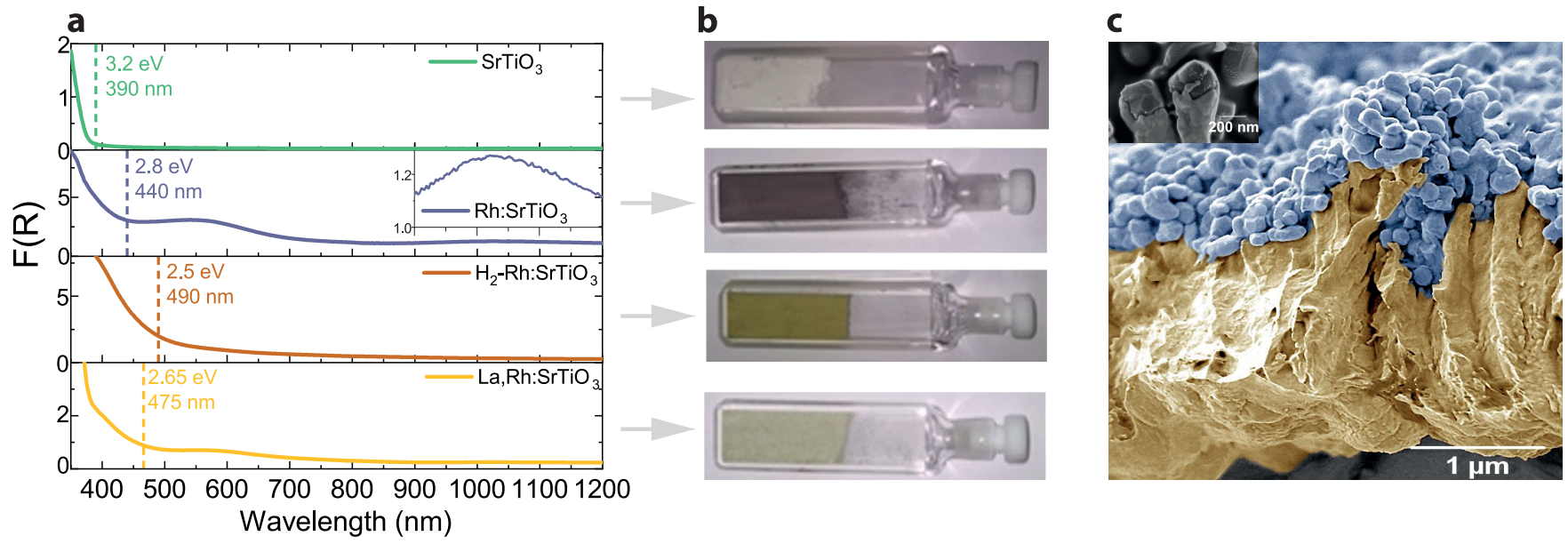

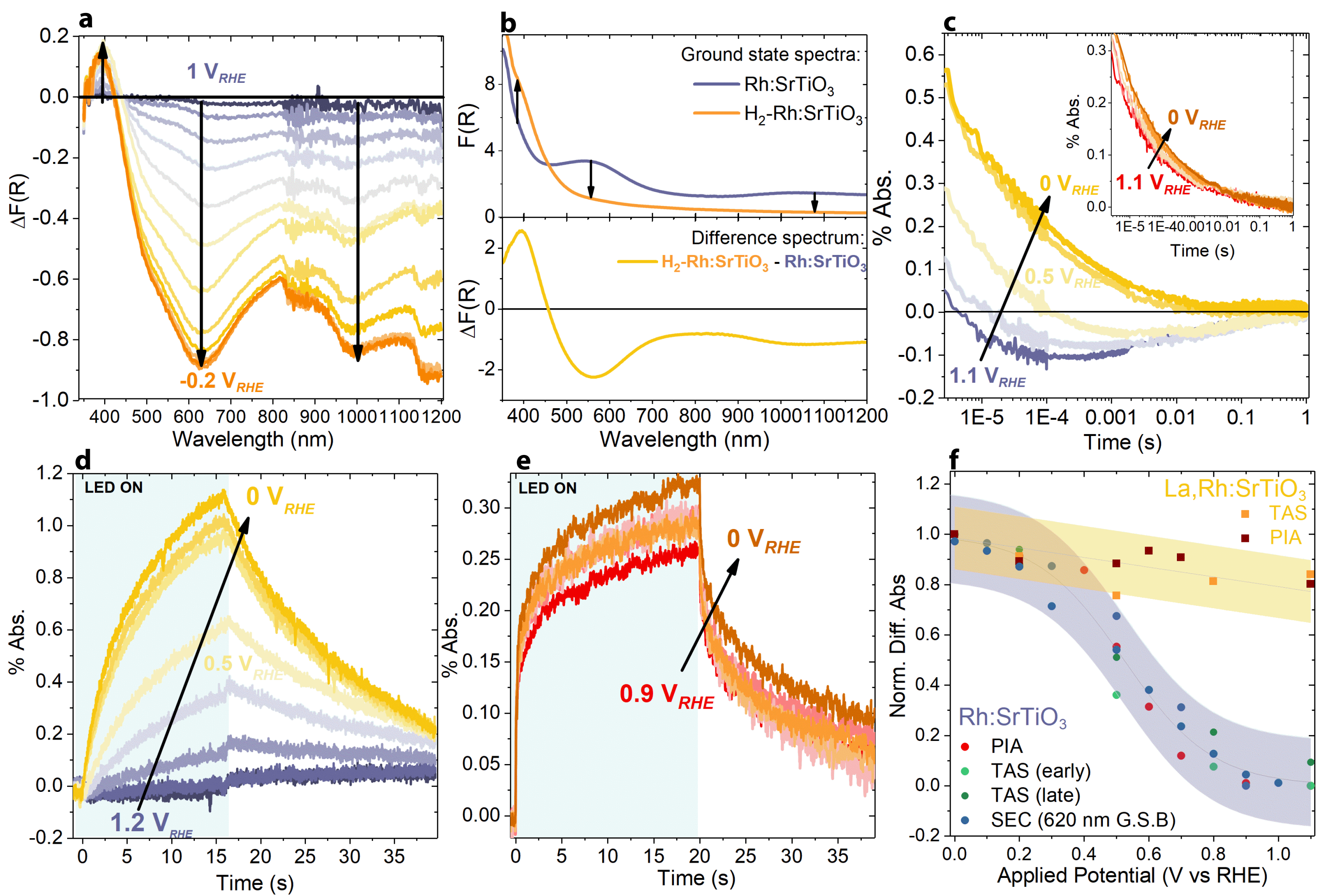

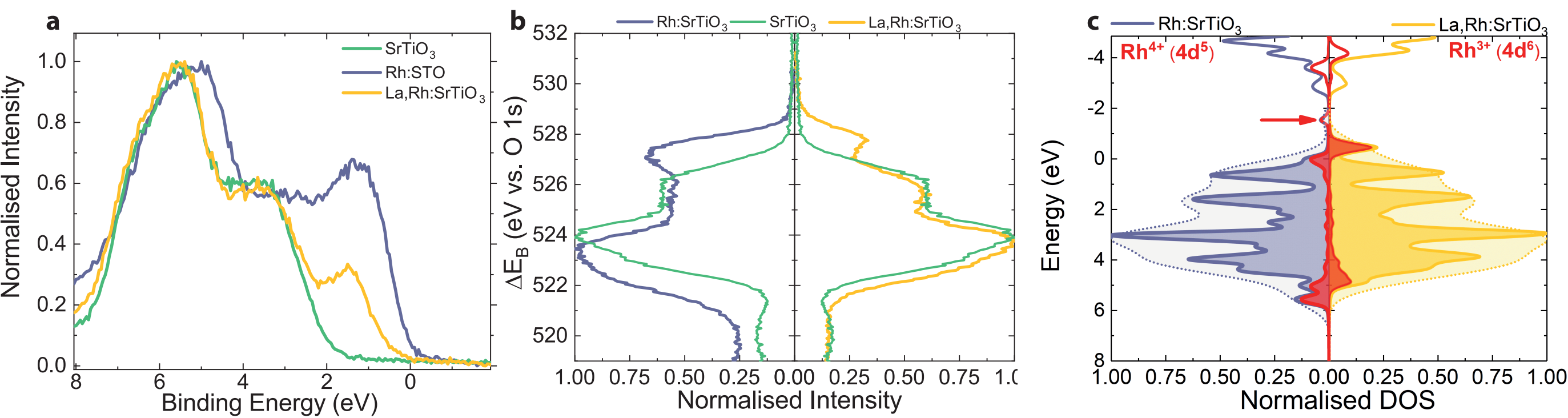


\section{$\mathrm{SrTiO}_{3}$ \\ Rh:SrTiO ${ }_{3} \quad$ La, Rh:SrTiO}

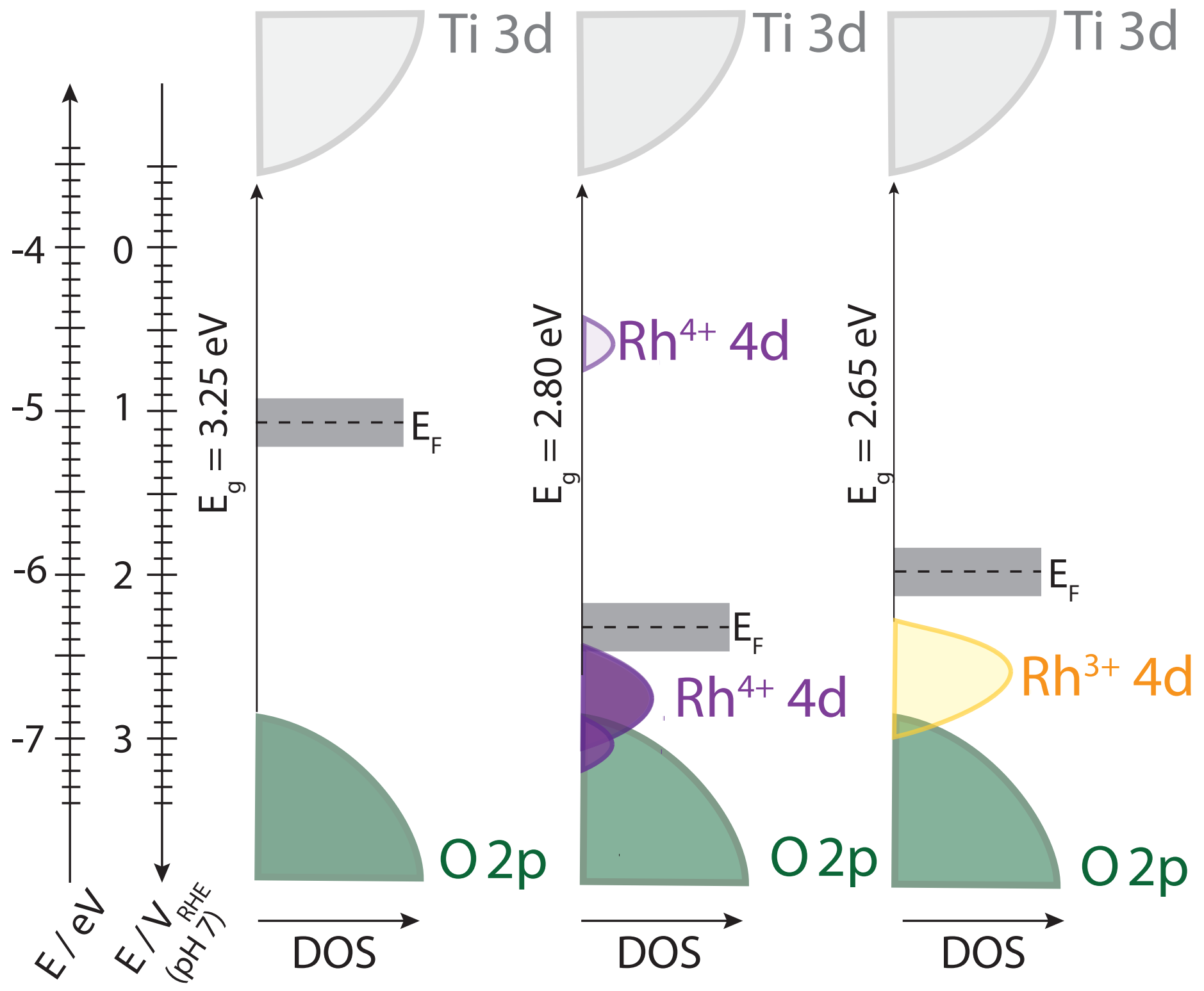




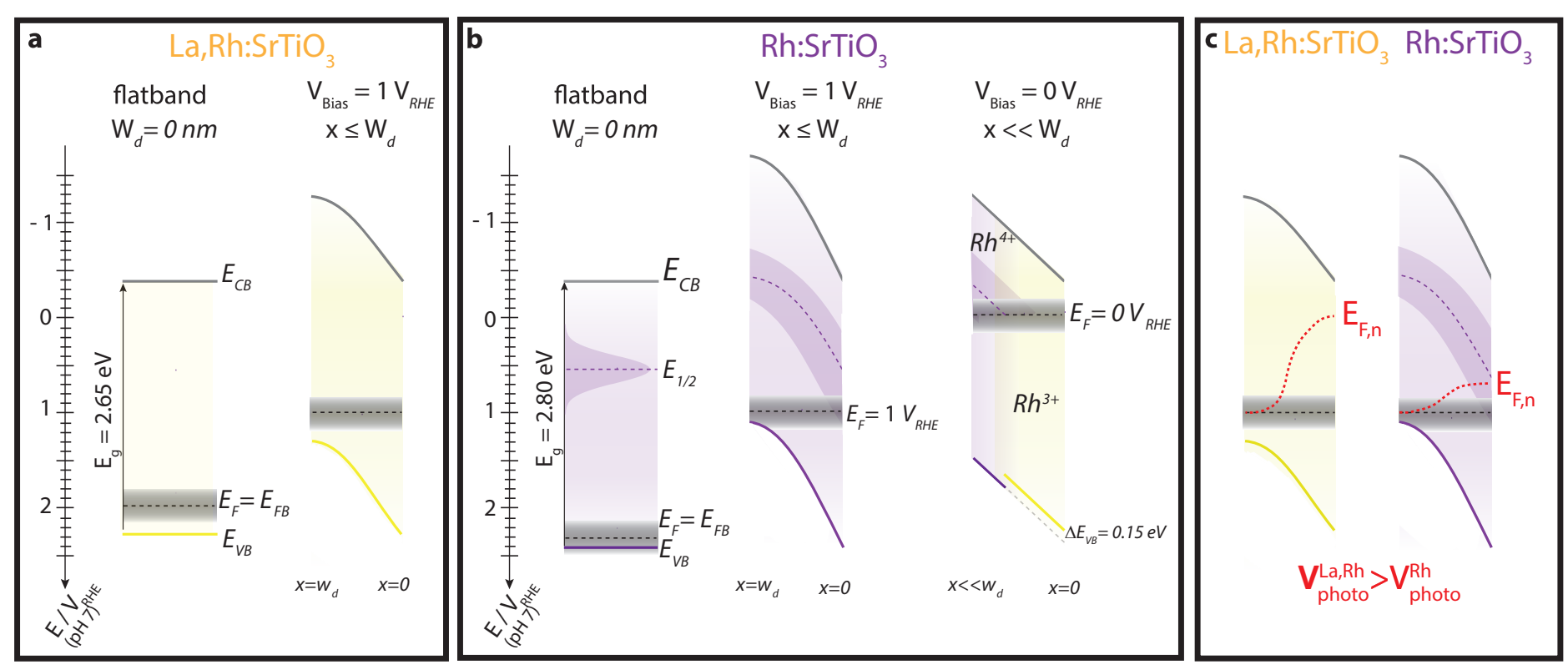




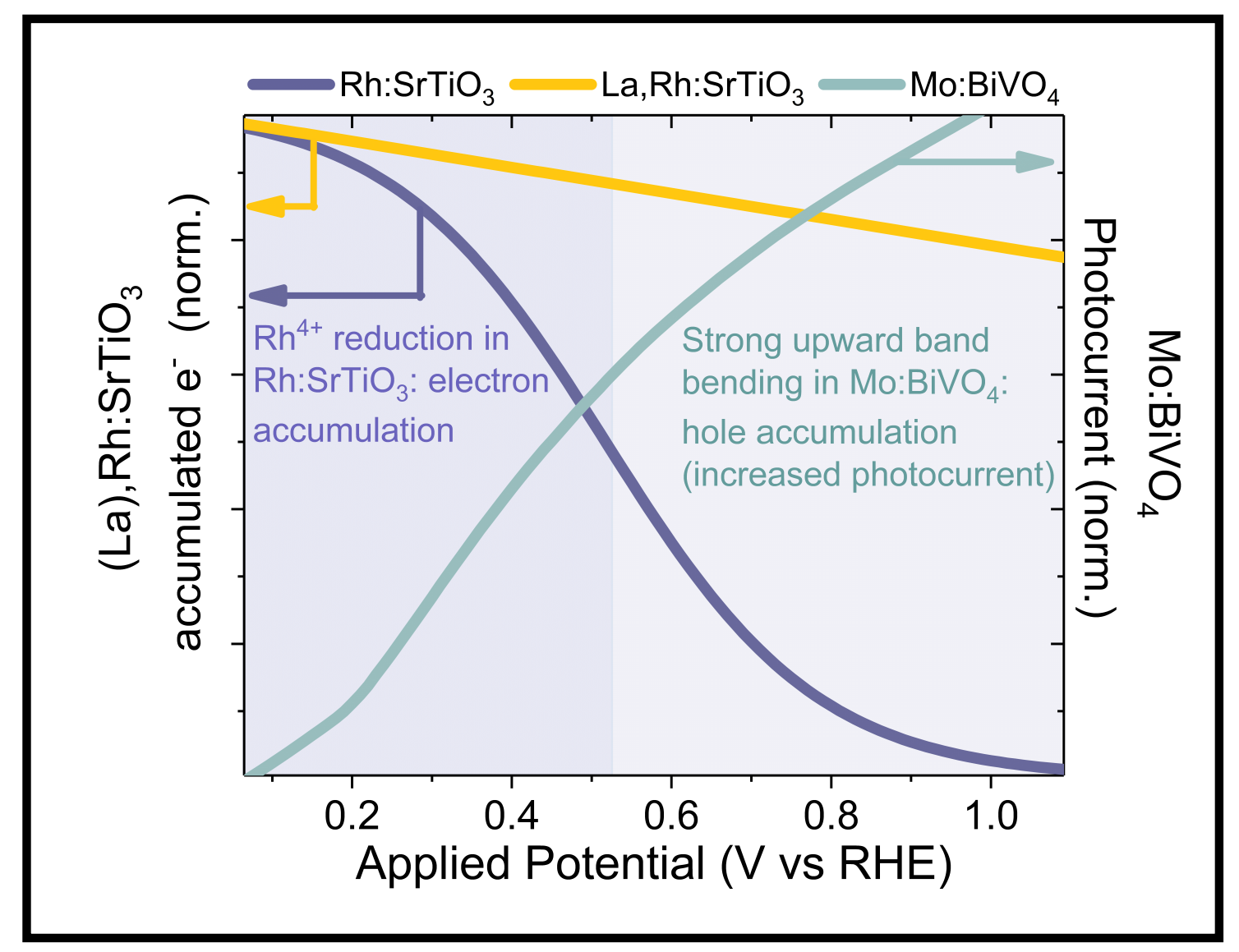

